
\title{
Resesarch Sulure \\ Heterosis for Biomass-Related Traits in Interspecific Triploid Hybrids of Willow (Salix Spp.)
}

Craig H. Carlson

Cornell University

Lawrence B. Smart ( $\nabla$ lbs33@cornell.edu )

Cornell University https://orcid.org/0000-0002-7812-7736

\section{Research Article}

Keywords: hybridization, hybrid vigor, polyploidy, short rotation coppice, woody plants, Salicaceae

Posted Date: April 8th, 2021

DOI: https://doi.org/10.21203/rs.3.rs-353369/v1

License: (c) (1) This work is licensed under a Creative Commons Attribution 4.0 International License. Read Full License

Version of Record: A version of this preprint was published at BioEnergy Research on July 7th, 2021. See the published version at https://doi.org/10.1007/s12155-021-10305-0. 
1 Heterosis for Biomass-Related Traits in Interspecific Triploid Hybrids Of Willow (Salix

2 Spp.)

3

4 Craig H. Carlson and Lawrence B. Smart ${ }^{\S}$

5

6 Horticulture Section, School of Integrative Plant Science, Cornell University, Cornell AgriTech,

7 Geneva, NY 14456 USA

8

§Corresponding Author:

Lawrence B. Smart

Address: 630 West North St., Geneva, NY, 14456

12 Email: lbs33@cornell.edu

13 Phone: $315-787-2490$

Contact Information:

CHC: chc89@ cornell.edu (ORCiD: 0000-0003-2050-5455)

LBS: lbs33@cornell.edu (ORCiD: 0000-0002-7812-7736)

Running Title: Heterosis in triploid willow

\section{Abstract}

21 Species hybridization is key for the improvement of shrub willow (Salix spp.) bioenergy crops, 22 because hybrids often display heterosis for yield. Development of high-yielding genotypes requires numerous broad attempts at hybridization followed by field evaluation and selection for stable performance. Selection of improved shrub willow varieties for use as a bioenergy crop involves evaluation of full-sib progeny in family-based selection trials. Improving the accuracy

26 of evaluation would greatly improve the efficiency of selection. Heterosis for biomass yield in

27 intra- and interspecific $\mathrm{F}_{1}$ and $\mathrm{F}_{2}$ shrub willow (Salix spp.) was examined utilizing a suite of biomass, foliar, and physiological traits collected over the course of 12 weeks in the greenhouse and over two years in the field. Triploid families generated from diploid $S$. viminalis and tetraploid S. miyabeana displayed the greatest levels of heterosis for harvestable biomass and 
31 biomass-related growth traits in the greenhouse and in the field. While intraspecific S. purpurea

32 diploids exhibited low levels of heterosis for these traits, interspecific diploids produced

33 moderate levels of heterosis in greenhouse experiments. Differences between greenhouse and

34 field trial results can largely be explained by pest damage, which negatively impacted

35 interspecific diploids. Heterosis for the traits that form the basis for biomass yield, including

36 stem growth, foliar, and physiological traits, was quantified and family-level differences are

37 discussed.

38 Key Words: hybridization, hybrid vigor, polyploidy, short rotation coppice, woody plants,

39 Salicaceae

40 Word count: 5808 words 


\section{Introduction}

42 Shrub willows (Salix spp., Salicaceae) are vigorous woody perennials that can be harvested to 43 provide feedstocks for biofuel and bioenergy production [1]. Commonly found as pioneer

44 species and in riparian habitats, the range of Salix extends from the arctic plains to the subtropics, with more than 350 species have been described [2,3]. Salix spp. are dioecious outcrossing perennials that are mostly entomophilous with possible low proportions of anemophily [4,5]. As Salix is particularly amenable to wide-hybridization, taxonomic characterization within the genus has been an enduring challenge for botanists and breeders alike [6]. In sympatric populations of Salix, members within the same section will often hybridize, which can generate mixed populations of both pure species and species hybrids [7]. In addition, vegetative clonal propagation can be a significant contributor to population structure in Salix, and has been shown to be fairly common in naturalized stands of North American S. purpurea [8]. Beyond the tremendous ecological amplitude, the heterogeneity and adaptive plasticity of Salix delivers a prodigious source of germplasm for genetic improvement.

Modern domestication of Salix traces back to the Swedish geneticist Nils Heribert-Nilsson's early cytological studies of S. viminalis $\times$ S. caprea hybrids in the 1920's [9]. Shortly thereafter, willow conservation and breeding was principally led by H.P. Hutchinson and K.G. Scott for nearly 30 years at the Long Ashton Experiment Station in the UK. Since the 1970's, breeders have maintained a goal of producing fast-growing shrub willow bioenergy feedstock cultivars that are high-yielding, genetically diverse, resistant to pests and diseases, and amenable to

62 breeding can be found in [11].

While most complex quantitative traits, including yield, generally display additive inheritance,

64 deviations from the midparent value in the $\mathrm{F}_{1}$ can result in either hybrid vigor or hybrid necrosis

65 [12]. Since the Green Revolution, the phenomenon of hybrid vigor (heterosis) has been exploited in crop systems, more than doubling global commodity yields in only a few decades. Plants

67 expressing heterosis are thought to have experienced one or more duplication events in their past

68 [13] and many crop plants are polyploid. There is no unifying model to predict heterosis in

69 interspecific hybrid plants, while much of the body of literature has been centered on the

70 comparison of hybrids generated from inbred or synthetic allopolyploids. Common in Salix, 
71 polyploidy is thought to be largely due to allopolyploidization events [14]. Polyploidy via chromosome doubling or wide hybridization can have a positive impact on the accumulation of biomass in hybrids, compared to progenitors [15]. In most plant crops, aneuploidy generally corresponds with hybrid necrosis due to the negative impact of sub-optimal gene dosages on protein function and metabolic homeostasis [12].

In order to advance the adaptive capacity of the US agricultural and energy sectors to respond to climate change, plant breeders must develop regionally adapted and sustainable bioenergy crops displaying hybrid vigor. Shrub willow has emerged as a highly sustainable bioenergy feedstock that can directly substitute for fossil fuels with great potential for yield increases through species hybridization. Through careful hybridization, phenotypic evaluation, and selection, substantial improvements have been made in shrub willow biomass yield [16] and lignocellulosic composition (quality) [17]. Species hybridization is a key component in the development of shrub willow bioenergy crops, as hybrids often display heterosis for yield [18]. Interspecific hybridization is also thought to be important in the generation of diverse secondary metabolites, and that selection may favor plants expressing novel profiles [19]. For instance, interspecific shrub willow populations have been implicated in enhanced resistance to pests [20,21] and pathogens [22], and has been attributed to differential expression of metabolites [23,24], resistance genes [21], as well as overall increased vigor [25].

Although heterosis has been observed in intraspecific crosses [26], it is more pronounced in triploids derived from the hybridization of diploid and tetraploid parents [27]. Ever since Nilsson-Ehle (1936) first reported finding naturally occurring "gigas" triploid Populus tremula L. in the forests of Sweden [28], polyploids have garnered substantial interest in tree breeding and research. Previous shrub willow yield trials have shown that elite triploid hybrid cultivars produce greater biomass yield compared to diploids and exceed or are not significantly different from tetraploids [29]. In addition, there is evidence that triploids have the potential to produce more cellulose per unit area because of higher biomass yields and/or cellulose content [17]. However, little is known about the genetic mechanisms responsible for heterosis in triploid willow [30] because there has been no systematic survey of heterosis from triploids.

The inherent time and investment associated with cultivar development in woody perennial feedstocks require efficient population development and phenotypic evaluation methods to 
101

102

103

104

105

106

107

108

109

110

111

112

113

114

115

116

117

118

119

120

121

122

123

124

125

126

127

128

129

significantly increase gains in biomass yield. Evaluation of large populations of progeny will be necessary to make significant gains, which requires early screening to reduce the costs associated with long-term field trials. The families referenced in this study were generated from crosses made between parents of differing ploidy and taxonomic section within the genus Salix, involving diploid S. purpurea and tetraploid S. miyabeana in the Sect. Helix Dumont, and diploid S. viminalis in the Sect. Vimen (formerly Viminella Seringe). The main objectives of this study were (1) to compare and contrast extensive phenotypic data collected among eight intraand interspecific shrub willow families, (2) to determine the extent to which these families display heterosis for biomass-related traits and biomass yield, and (3) determine if there is concordance of heterosis when plants are grown in the greenhouse compared with the field.

\section{Materials and Methods}

\section{Population Development}

A total of eight full-sib $F_{1}$ and $F_{2}$ families were generated from crosses between diploid and tetraploid parents representing three Salix species: $S$. purpurea Sect. Helix $(2 \mathrm{n}=2 x=38), S$. viminalis Sect. Vimen $(2 \mathrm{n}=2 \mathrm{x}=38)$, and $S$. miyabeana Sect. Helix $(2 \mathrm{n}=4 x=76)$. The full-sib $\mathrm{F}_{1} S$. purpurea family 82 was generated from a cross between female 94006 and male 94001, both collected from naturalized $S$. purpurea populations in upstate NY. Two $\mathrm{F}_{1}$ offspring from this cross, female S. purpurea 'Wolcott' (9882-41) and male S. purpurea 'Fish Creek' (9882-34), were crossed to generate the full-sib $\mathrm{F}_{2} S$. purpurea family 317 . The female $S$. purpurea genotype 94006 was crossed with the male S. viminalis 'Jorr' to generate the interspecific diploid family 407, and a cross between $S$. viminalis $07-\mathrm{MBG}-5027$ and the male $S$. purpurea genotype 94001 generated the 'pseudo-reciprocal' interspecific family 421. Female diploid genotypes 94006 and 07-MBG-5027 were separately crossed with tetraploid S. miyabeana male 01-200003, to generate the interspecific triploid families 415 and 423, respectively. Triploid family 430 was generated from a cross between the tetraploid S. miyabeana female 01-200-006 and diploid S. viminalis male 'Jorr'. Finally, the intraspecific $S$. miyabeana tetraploid family 425 resulted from a cross between female 01-200-006 and male 'SX64'. All family progeny individuals and their parents were planted in nursery beds at Cornell AgriTech (Geneva, NY).

\section{Greenhouse Design}


Parent genotypes and randomly chosen progeny from the eight families described above were grown from stem cuttings $(20 \mathrm{~cm}$ ) in 12-L plastic pots with peat moss-based potting mix (Fafard, Agawam, MA) to evaluate growth traits under greenhouse conditions over the course of 12 weeks. Families consisted of 12 progeny individuals and their parents, for a total of 104 genotypes (Table 1). One exception is that the male parent 'SX64' of the intraspecific $S$. miyabeana family 425 was not included. Plot was defined as a single cutting planted in a pot, which were arranged in a randomized complete block design with four replicate blocks. Two blocks were located on benches in one greenhouse with the other two blocks in an adjacent greenhouse set for identical growing conditions. Supplemental greenhouse lighting was provided on a 14-h day : 10-h night regimen with max daytime temperature of $26^{\circ} \mathrm{C}$ and a nighttime temperature of $18^{\circ} \mathrm{C}$. Liquid fertilizer (Peter's 15-16-17 Peat-Lite Special ${ }^{\circledR}$, Scott's, Marysville, $\mathrm{OH})$ was applied weekly after week four according to manufacturer recommendations.

\section{Field Design}

The field trial was established at Cornell AgriTech (Geneva, NY) in a randomized complete block design with four replicate blocks of three-plant plots. To avoid edge effects, S. purpurea parent genotypes 'Fish Creek' and 94006 were planted as border rows along the east and west sides of the trial, respectively, and the north and south ends were buffered by a single row of genotype 94006. Within-row spacing was $0.4 \mathrm{~m}$ and spacing between rows was $1.82 \mathrm{~m}$. The soil at the field site is Odessa silt loam with a depth to water table of 25 to $45 \mathrm{~cm}$. For additional site characteristics, see [30,31].

\section{Determination of Ploidy Level}

The relative DNA content (2C-value in pg) of family parents and progeny was determined by flow cytometric analysis using young leaf material harvested from actively growing shoots in greenhouse conditions. Analysis of $50 \mathrm{mg}$ of mature leaf tissue from parental genotypes and selected progeny was performed at the Flow Cytometry and Imaging Core Laboratory at Virginia Mason Research Center in Seattle, WA. A minimum of four replicates of all samples were independently assessed using either the diploid $S$. purpurea female genotype 94006 or the diploid S. purpurea male genotype 94001, and the tetraploid S. miyabeana female genotype 01200-006 or the tetraploid S. miyabeana male genotype 01-200-003 as internal standards. Diploid and tetraploid parent genotypes from multiple runs were averaged and then divided by the value 
of the check for that run. This factor was then multiplied by each sample value within the same run as the check. When a genotype was analyzed more than once, the $\mathrm{pg} 2 \mathrm{C}^{-1}$ values were averaged.

\section{Greenhouse Phenotypes}

Starting approximately $7 \mathrm{~d}$ after planting (dap), the vegetative phenology stage (PHE) of each plot was scored at 7, 9, 11, 13, and 15 dap. Vegetative phenology was scored as six stages described as: stage (0) dormant axillary buds are tightly closed and covered by bud scales; (1) axillary buds begin to swell and change color; (2) generative bud burst with visible leaves; (3) leaves emerge and begin to unfold; (4) unfolded leaves begin expanding; and (5) at least two leaves are fully expanded. To provide an indirect measurement of leaf chlorophyll and nitrogen content, leaf color was measured using a Minolta SPAD 502 Chlorophyll Meter (Spectrum Technologies, Inc., Aurora, IL). Four fully-expanded leaves sampled from the upper $25 \%$ of the canopy were measured and averaged for each plant at 14, 42, and 70 dap. Sex of progeny individuals was determined by visual observation after forcing 2-3 dormant shoots to flower in greenhouse conditions an $\mathrm{d}$ was confirmed in field trial plots.

Primary stems were defined as those emerging from dormant axillary buds and $\geq 6 \mathrm{~cm}$ in length. Secondary stems were defined as emerging from axillary buds on the primary stem from currentseason growth (sylleptic) and were counted as the total number of secondary branches within each plot with a PHE $\geq 3$. The length of each stem per plant was measured from the proximal base of the primary stem to the distal inner-whorl of the leaf primordia. The sum of stem lengths for each plot was considered to be the total stem length (TSL) and mean stem length (MSL) per plant was the mean of individual stem lengths. Starting 14 dap to 70 dap, all primary stems were measured within each plot once a week, totaling nine measurement time points.

The diameter of each primary stem within a plot (SDIA) was measured at the base the final week of the study using a digital caliper. Stem diameter measurements were used to calculate the area (SA) of all stems $>20 \mathrm{~cm}$ in length. Sum of stem area per plant (SSA) was calculated by summing individual SA per plant. An estimate of total stem volume (VOL) was modeled as a cone by multiplying SSA times $1 / 3$ plot height. 
In order to predict root biomass (RDW), root electrical capacitance (REC, $\mathrm{nF}$ ) was measured according to the protocol described in [32]. Root biomass was harvested from a subset of 20 pots (2-3 progeny individuals per family) that were selected from the 416 pots as representing a distribution of capacitance readings, ranging from 70.5 to $283.8 \mathrm{nF}$. To assure the retrieval of fine root hairs, potting mix was washed from roots by first soaking root balls in water for $12 \mathrm{~h}$ without their pots then rinsing them by hand repeatedly and decanting into $2.4 \mathrm{~mm}$ and $1.0 \mathrm{~mm}$ aluminum test sieves. Root samples were considered appropriate for dry weight analysis when root biomass was visually free of debris. Root biomass and cuttings were separately dried in an oven and weighed.

Leaf area (LFA) was determined using a portable leaf area meter (Model No. CI-203, CID Inc., Camas, WA). A representative leaf from each plot was scanned, then excised, dried to constant weight at $65^{\circ} \mathrm{C}$, and weighed to obtain leaf dry weight (LFDW). Leaf petioles were excluded from LFA and LFDW measurements. Specific leaf area (SLA) was calculated as the ratio of the total leaf area $\left(\mathrm{cm}^{2}\right)$ and dry weight $(\mathrm{g})$. Leaf aspect ratio (LFR) is the ratio of the leaf length to its maximum width. Leaf shape factor (LFF) or the ratio of leaf area to the leaf perimeter, was corrected so that the shape factor of a circle is equal to one: $4 \pi\left(L F A / L F P^{2}\right)$. Stem and leaf biomass was harvested separately from each plot, dried in an oven to constant weight at $65^{\circ} \mathrm{C}$, then weighed to determine total stem dry weight (SDW) and total leaf dry weight (LDW).

\section{Field Phenotypes}

During the dormant period after each growing season, DIA of stems $\geq 5 \mathrm{~mm}$ were measured at 30 $\mathrm{cm}$ from the base of the plant using Masser Racal 500 digital caliper (Masser, Rovaniemi, Finland) and stem number was counted for each plant. The SA of each stem was calculated from DIA and SSA per plant was calculated by summing the areas of every stem. Maximum stem height (HT) of every plot was recorded using a measuring rod (Crain Enterprises, Inc., Mound City, IL).

Physical and chemical wood properties were measured for four replicates. Stem segment samples were collected in the dormant period after each growing season using sampling methods previously described (Liu et al., 2015) and were stored frozen at $-4^{\circ} \mathrm{C}$ until they were processed. The specific gravity of each sample was measured by volumetric displacement (TST om-06, 2006). In 2014, a modified method of measuring specific gravity was used where the volume of 
water displaced was weighed for added precision. Following specific gravity determination, stem segments were oven-dried at $65^{\circ} \mathrm{C}$ to a constant weight and then rough milled to a $5 \mathrm{~mm}$ particle size with a Retch SM300 cutting mill (Retch, Haa, Germany) and were further comminuted to $<0.5 \mathrm{~mm}$ particle size by fine milling with the IKA MF 10.1 knife mill (IKA, Wilmington, NC) for compositional analysis. Approximately $20 \mathrm{mg}$ of each milled stem sample was analyzed with a Thermogravimetric Analyzer (TGA) Q500 instrument and Universal Analysis 2000 version 4.5A software (TA Instruments, New Castle, DE), as previously described (Serapiglia et al., 2009). Hemicellulose, cellulose, lignin, and ash content were determined as a percentage of total dry biomass for each sample, as previously described in [30].

At the end of the second growing season, crown diameter (CDIA) was measured using modified Haglöf Mantax forestry calipers (Haglöf Sweden AB, Långsele, Sweden). Stool diameters were measured at $15.24 \mathrm{~cm}$ above the soil, which is the average height of a shrub willow harvester. Crown form (FORM) was calculated by multiplying the arctangent 2 of one-half CDIA and the fixed distance at which CDIA was measured $(15.24 \mathrm{~cm})$ by $180 / \pi$, to obtain the angle of the stem branching relative to the soil.

\section{Statistical Analysis}

All statistical analyses and plotting were performed within the open-source statistical computing environment, R [33]. For quantitative traits listed in Table 2, a Shapiro-Wilk test was conducted to detect a significant departure from normality. For non-normal data, the boxcox function was used to maximize the Shapiro-Wilk W statistic by computing log-likelihoods for the parameter ( $\lambda$ ) of the Box-Cox power transformation, such that either a single-parameter $\left(y^{\lambda}-1\right) / \lambda$ or twoparameter $\left[\left(y-\lambda_{2}\right)^{\lambda_{1}}-1\right] / \lambda_{1}$ power transformation was applied. For repeated measurements of quantitative traits HT, MSL, and TSL, growth rates were determined using Gompertz 3parameter function: $c e^{-e^{-a(t-b)}}$, whereas ordinal PHE and PSN growth rates were determined using the following 3-parameter logistic function: $c /\left(1+e^{-a(t-b)}\right)$, where, $a$ is the growth rate, $b$ is the inflection point, $c$ is the asymptote, and $t$ is time (in dap).

Tests for association between binary and quantitative traits were done using Pearson's product moment correlation coefficient $(r)$ at a confidence level of $95 \%$. Correlations between ordinal and quantitative or binary trait pairs were tested using Spearman's rank correlation coefficient, 
247 whereas Kendall's rank correlation was used to test ordinal trait pairs. To correct for multiple comparisons, a Bonferroni correction was applied by multiplying $P$-values by the number of pairwise comparisons. Genotypes were divided based on ploidy, sex, and pedigree. A Wilcoxon Rank Sum test was used to test whether two sample distributions differ. When significant differences were observed, treatment comparisons were performed using Tukey's Range test. Variance components for the greenhouse trial were estimated with lmer in the package lme4 [34] using the Restricted Maximum Likelihood (REML) method, for the following model:

$$
y_{i j}=\mu+\alpha_{i}+\beta_{j}+\varepsilon_{i j k}
$$

where $y_{i j k}$ is the observed value, $\mu$ is the overall mean, $\alpha_{i}$ is the effect of genotype $i, \beta_{j}$ is the effect of block $j$, and $\varepsilon_{i j k}$ is the random error, which is assumed independent and identically distributed.

Field trial dimensions were $388.6 \mathrm{~m} \times 36.6 \mathrm{~m}$ (Supplementary Fig. S1), which introduced spatial variation not easily accountable by block alone. Thus, to account for spatial variation in the field trial, following the approach outlined in [35], spatial trends (row and column) in the field trial were modeled as two-dimensional Penalized (P)-splines, using SpATS and SAP functions (n.seg $=(16,64)$, tolerance $\left.=1 \times 10^{-6}\right)$ in the SpATS package [36]. The conditional means of random effects were extracted from the above linear mixed model in order to provide the relative phenotypic contributions of the male and female parents. Midparent heterosis (MPH) was calculated as the percent deviation of the $\mathrm{F}_{1}$ progeny mean relative to the geometric mean of the parents. In this case, genotype (clone) was fixed in the linear model, so MPH represents deviations from these estimates. Fisher's Exact test was used to classify phenotypic expression into modes of inheritance $(P<0.05)$ by comparing the deviation of the $\mathrm{F}_{1}$ to each parent. For the reason that the male parent of the intraspecific tetraploid $\mathrm{F}_{1} S$. miyabeana family 425 , cv. 'SX64', was not present, only the deviation of the $\mathrm{F}_{1}$ from the female parent 01-200-006 was reported.

\section{Results and Discussion}

\section{Harvestable Biomass in the Greenhouse Trial}


274 Of the 104 genotypes harvested in this trial, total aboveground biomass (AGB, g) ranged from

$275119.6 \mathrm{~g}$ to $51.1 \mathrm{~g}$ (Fig. 1). The greatest yielding genotype was a triploid hybrid, $S$. viminalis $\times S$.

276 miyabeana 12X-423-043, and the least yielding genotype was a diploid S. purpurea, 10X-082-

277 078. The greatest mean AGB was from the S. viminalis $\times$ S. miyabeana triploid family 423

$278(100.3 \pm 3.8)$ and the S. miyabeana $\times$ S. viminalis triploid family $430(98.7 \pm 3.4)$, followed by the

279 S. viminalis $\times S$. purpurea diploid family $421(92.3 \pm 3.8)$. All other families were not

280 significantly different from one another, with a family mean AGB ranging from 78.9 to $82.5 \mathrm{~g}$.

281 The mean AGB of triploids $(93.8 \pm 1.6)$ was significantly greater (Wilcoxon $P<0.001)$ than the

282 mean AGB of diploids (82.6 \pm 1.3$)$ and tetraploids $(79.8 \pm 2.6)$. While the triploid families 423

283 and 430 did show greater AGB than both diploid and tetraploid parents, AGB did not exceed the

284 midparent for the triploid family 415 (Fig. 2). Similarly, belowground dry biomass (RDW, g),

285 which was estimated using the REC method described in [32], ranged from $11.1 \mathrm{~g}$ to $42.5 \mathrm{~g}$, with

286 the triploid family 430 had accumulating the greatest RDW, followed by families 423 and 421 ,

287 with the lowest mean family REC values from the $S$. purpurea $\times S$. miyabeana family 415 . The

288 mean RDW of triploids $(26.6 \pm 0.8)$ was significantly greater (Wilcoxon $P<0.001)$ than that of

289 diploids $(23.1 \pm 0.6)$ and tetraploids $(22.2 \pm 0.9)$, with no significant difference between diploids

290 and tetraploids (Wilcoxon $P=0.57$ ) (Fig. 1c).

291 Biomass ratios LDW SDW ${ }^{-1}$ and $\mathrm{RDW} \mathrm{SDW}^{-1}$ for tetraploid genotypes were significantly

292 greater than those of triploids and diploids (Wilcoxon $P<0.001$ ), whereas diploids had

293 significantly lower LDW SDW ${ }^{-1}$ and $\mathrm{RDW} \mathrm{SDW}^{-1}$ ratios compared to both triploids and

294 tetraploids (Wilcoxon $P<0.001$ ) (Fig. 1d). The tetraploid S. miyabeana family 425 had the

295 greatest $\mathrm{LDW} \mathrm{SDW}^{-1}$ ratio $(0.76 \pm 0.02)$ and the triploid $S$. miyabeana $\times S$. viminalis triploid

296 family 430 had the greatest $\mathrm{RDW} \mathrm{SDW}^{-1}$ ratio $(0.53 \pm 0.02)$. Further, the diploid $\mathrm{F}_{2} S$. purpurea

297 family 317 had the lowest $\mathrm{LDW} \mathrm{SDW}^{-1}$ ratio $(0.50 \pm 0.01)$ and the triploid $S$. purpurea $\times S$.

298 miyabeana family 415 had the lowest RDW SDW ${ }^{-1}$ ratio $(0.38 \pm 0.02)$, yet was not significantly

299 different from both intraspecific $F_{1}$ and $F_{2} S$. purpurea families. Subsequently, the ratio of SDW

300 to the total biomass (TBM) showed the converse, which suggests that diploids placed

301 considerably less energy into leaf biomass production (28.9 \pm 0.4$)$ compared to triploids (36.6

$302 \pm 0.6$, Wilcoxon $P<0.001)$ and tetraploids $(34.4 \pm 1.4$, Wilcoxon $P<0.001)$.

303 Biomass-Related Stem Growth in the Greenhouse 
Growth measurements taken at the end of the study included the length and diameter of every stem, as well as primary and axial stem number. The greatest plot HT after 84 dap in the greenhouse was observed for the triploid hybrid, S. viminalis $\times$ S. miyabeana $12 \mathrm{X}-423-034$ (2.1 \pm 0.05 ), whereas the genotype with the lowest HT was the intraspecific tetraploid, S. miyabeana 12X-425-106 (1.2 \pm 0.09$)$. Total stem length (TSL) was calculated as the sum of the length of each shoot $>20 \mathrm{~cm}$ per plot, and ranged from $6.03 \mathrm{~m}$ to $1.95 \mathrm{~m}$. While TSL of diploids ( 3.89 \pm 0.08 ) and triploids ( $3.88 \pm 0.10$ ) was not significantly different (Wilcoxon $P=0.85$ ) at 84 dap, tetraploids showed significantly less TSL $(3.47 \pm 0.13)$ than diploids (Wilcoxon $P=0.02$ ) and triploids (Wilcoxon $P=0.01$ ). The lower TSL values for tetraploids may be explained by lower PSN and ASN after 84 dap, thus leading to fewer stems and lower TSL than diploids and triploids. Although triploids had a greater MSL $(1.62 \pm 0.02)$ at 84 dap (Wilcoxon $P<0.001$ ), diploids $(1.44 \pm 0.02)$ and tetraploids $(1.49 \pm 0.04)$ were not significantly different (Wilcoxon $P=$ 0.11). The sum of DIA sampled were used to calculate MDIA and sum stem area (SSA) for each plot. The MSA ranged from 0.37 to $1.41 \mathrm{~cm}^{2}$ and SSA ranged from 1.29 to $2.95 \mathrm{~cm}^{3}$.

\section{Sex Ratio Bias}

While the selection of individuals for each family was completely random, all families had a greater proportion of female progeny, of which five of the eight families were sex-biased $\left(\chi^{2} P<\right.$ 0.05 ) (Table 1). Female to male sex ratios ranged from 1.13 to 4.56. Notably, the triploid $S$. miyabeana $\times$ S. viminalis family 430 was all-female. Sex ratio bias is not uncommon in willows (primarily female-biased) [37-43], but infrequently found in poplars (primarily male-biased) [44]. Whether influenced by environmental factors, unique mechanisms of sex determination, or sex chromosome dosage, the genetic basis of biased sex-ratios in Salix reported here and elsewhere are not known.

\section{Foliar and Physiological Traits}

Vegetative phenology recorded at 7, 9, 11, and 13 dap demonstrate significantly faster budbreak, leaf expansion, and early shoot development in triploids, compared with diploids and tetraploids (Fig. 3a). Diploids, while significantly lagging triploids and tetraploids early on, were not significantly different from tetraploids by 13 dap. For each plot, three SPAD readings were taken at 14, 42, and 70 dap to assess the chlorophyll content or nitrogen status of fully-expanded leaves from the upper $30 \mathrm{~cm}$ of the canopy. A significant interaction was identified for SPAD by time 
334

335

336

337

338

339

340

341

342

343

344

345

346

347

348

349

350

351

352

353

354

355

356

357

358

359

360

361

362

363

and ploidy as well as time and family. While the initial SPAD reading at 14 dap showed marginally greater values for triploids and tetraploids, the opposite trend was found for later readings (Fig. 3b). Diploid genotypes showed significantly greater SPAD readings at 42 dap than triploids and tetraploids, which were not significantly different. By 70 dap, differences in SPAD readings by ploidy were not as great as those taken at 42 dap. This was also observed for SPAD readings taken in the field trial, where higher ploidy was inversely correlated with greater SPAD readings.

Leaf measurements obtained at 11 weeks included leaf area (LFA), length (LFL), width (LFW), perimeter (LFP), ratio (LFR), and dry weight (LFDW). Of all the genotypes in the trial, the intraspecific tetraploid, S. miyabeana 13X-425-110, had the greatest LFA (40.0 \pm 7.5$)$, whereas the diploid hybrid, $S$. purpurea $\times S$. viminalis $11 \mathrm{X}-407-087$, had the smallest LFA (8.9 \pm 1.6$)$. On a family-level, the intraspecific S. miyabeana family 425 had the greatest LFA $(22.0 \pm 1.2)$ and the intraspecific $F_{1} S$. purpurea family 82 had the smallest LFA (13.9 \pm 0.5$)$. Mean LFL ranged from $17.5 \mathrm{~cm}$ to $6.6 \mathrm{~cm}$. Among the top $50^{\text {th }}$ percentile for the leaf dimensions LFA, LFL, and LFW, nearly all genotypes had either the S. viminalis female 07-MBG-5027 or the S. viminalis male 'Jorr' as a parent.

Given that all plots received the same fertilizer and application rate, it may be that the nitrogen status of leaves is concentrated to less leaf area in diploids, given the significantly greater SPAD values in diploids, compared with those of triploids and tetraploids. Further, LFA and LDW of triploid $\mathrm{F}_{1}$ individuals showed primarily additive inheritance, and on the basis of ploidy, triploids were intermediate to diploids and tetraploids for the same traits. Yet, under controlled environmental conditions, higher ploidy tended to result in greater leaf area and biomass, but a lower leaf nitrogen status. One possible explanation for this is that polyploid willows are more efficient in the production of low resource leaves [45]; perhaps by focusing available nutrient resources to a rapidly emerging canopy, rather than uniformly along the stem, as is likely the case in diploids. Triploid genotypes with an intermediate $\mathrm{LDW} \mathrm{SDW}^{-1}$ ratio could indicate more efficient partitioning of photoassimilate from leaves to sink organs. While this attribute would surely stimulate the rapid accumulation of biomass, diploids could benefit in nutrient-scarce environments by sustaining growth rates, whereas higher ploidy levels would likely show an overall reduction in their growth rate. 


\section{Multivariate Analysis}

Traits that were non-informative in biomass yield predictions, but correlated with informative predictors, may still prove to be of relative importance, particularly when assayed in additional environments or pedigrees. While many of the traits listed in Table 2 were strongly correlated with those important for biomass yield, some pairs tended to be more autocorrelated (Supplementary Fig. S3), as they were repeated measurements or components of the same trait. The greenhouse-collected traits showing the highest correlations with SDW were VOL ( $r=$ $0.73)$, REC ( $r=0.78)$, and LDW ( $r=0.62)$; all grouping closely. Following these traits, later stem length measurements were most correlated to SDW, whereas, PHE at 11 and 13 dap and ASN at 56 dap were most correlated with LDW. Although weakly, both SDW and LDW had inverse relationships with the inflection point of HT.

Phenological stages (PHE) recorded at 11 and 13 dap in the greenhouse were strongly correlated with SPAD at 14 dap, LFR, LFL, TSL at 14 and 21 dap, and the growth rates of HT, MSL, TSL, but not STN. Early PHE measurements at 7 and 9 dap were positively correlated with CVAL and LFR. At 13 and 15 dap, PHE was only weakly correlated with SPAD at 42 dap. All PHE measurements were inversely correlated with LFW, SLA, and the ratio STN AGB ${ }^{-1}$. Leaf dimensions LFL, LFA, and LFP, as well as the biomass ratio LDW SDW ${ }^{-1}$ were strongly and positively correlated $(r>0.5)$ with CVAL, whereas both SPAD at 42 dap and SLA were inversely correlated $(r<-0.5)$. Besides showing positive correlations to the ratios SDW TOT ${ }^{-1}$ and STN AGB ${ }^{-1}$, SLA was the solitary trait to be inversely correlated with nearly all growth traits. Along with SLA, SDW TOT ${ }^{-1}$ and STN AGB ${ }^{-1}$ were most negatively correlated with leaf dimensions, as well as SPAD at 42 dap and STN measurements. Root electrical capacitance (REC), SSA, TSL at 28 dap, and PHE at 11 and 13 dap were highly correlated with SDW, and have been shown to account for a large proportion of the variance $\left(R^{2}=0.69\right)$ in multiple linear regression [32].

Repeated measures have commonly been used to identify growth patterns in response to environmental factors or treatments. Here, the treatments under consideration were pedigree and ploidy level. While the inherent differences between factors tend to inflate the actual differences (e.g., diploids versus tetraploids), relative growth rates (RGR) act as a standardized measure of growth and offer more impartial comparisons. Early vegetative PHE measurements showed that 
triploids are faster to break bud and grow at faster rates compared with diploids and tetraploids. However, over time, diploids maintained more linear growth rates compared with those of triploids, which leveled-off approximately 8 weeks after planting. This could be due to increasingly limited space in the pots of triploids, as they exhibited both greater above and below-ground biomass at the termination of the study, especially for individuals with $S$. viminalis as one of the parents, as described in [32]. It may be that $S$. viminalis crosses have a higher propensity for accumulating root mass than intraspecific or interspecific crosses of $S$. purpurea and S. miyabeana. Using the REC phenotyping method, genetic mapping of this trait could improve our understanding of root development and response to drought among willow crosses. Marker-assisted selection (MAS) for REC could subsequently be used to improve biomass yield, in the case that field evaluations correlate well with those in the greenhouse.

For field-collected biomass traits, all were highly correlated across years (Supplementary Fig. S4). However, foliar traits were positively, but more weakly correlated between years, besides leaf ratio $(\mathrm{LFR})(r=0.65, p<0.001)$ and leaf shape factor (LFF) $(r=0.35, p<0.001)$. Crown form (FORM) measurements for all three years measured were most inversely correlated with biomass stem growth traits (e.g., SA, HT, VOL, and STN) as well as wood density (DEN). Wood chemical composition traits were also highly correlated, whereby LIG and ASH were inversely correlated with CLS and HCL. Wood density (DEN) was only positively correlated with CLS, but inversely correlated with HCL and ASH. Overall, individuals with higher ploidy levels tended to have greater ASH and lower HCL, compared with diploids (Supplementary Fig. S5).

\section{Concordance of Heterosis for Common Greenhouse and Field Traits}

Field-collected traits for the same families resulted in similar levels of heterosis for common traits collected in the greenhouse trial (Fig. 4, Fig. 6). For instance, families 423 and 430 showed the greatest MPH for HT, SA, and VOL for both years in the field trial as well as in the greenhouse trial. While the interspecific diploid families 407 and 421 showed marginal levels of MPH for the same traits, it was not observed in the field trial as a result of a high-incidence of potato leafhopper and Japanese beetle feeding on individuals with a $S$. viminalis background, also described in [21]. Yet, this was not observed for triploid families with a diploid S. viminalis parent, which suggests some level of resistance in the hybrids. 
424 Of the two years in the field trial, foliar traits were shown to be the most variable between years

425 (Fig. 6, Supplementary Fig. S6). This was due to differences in precipitation during the 2015 and 2016 growing seasons. In 2015 growing conditions were nearly optimal throughout the season, but 2016 suffered a long stretch of mid-summer drought. Although individuals did not dramatically differ in MPH for most trait rankings between growing seasons, foliar trait MPH variation can be assessed by SLA. However, families 421, 423, and 430, which all had a $S$. viminalis parent, did show greater MPH for foliar traits in both the greenhouse and field trials. Remarkably, triploid individuals, 12X-423-060 and 12X-423-110, had average LFL >40 cm, which was nearly two-fold greater than the better parent.

\section{Midparent Heterosis and Patterns of Inheritance}

Our data show that relative to diploid and tetraploid genotypes triploids exhibit greater levels of heterosis for biomass yield and correlated growth traits, especially for crosses made between Salix Sections (Fig. 4, Supplementary Fig. S2). The interspecific diploid family 421 and interspecific triploid families 423 and 430 have S. viminalis as one of the parents, and all showed high levels of MPH (\%) for total SDW and RDW, as well as RGR and early TSL and PHE measurements. However, MPH for total biomass or stem growth measurements were not observed in interspecific $S$. purpurea $\times$ S. viminalis family 407 or the intraspecific $S$. purpurea or S. miyabeana $\mathrm{F}_{1}$ families.

The $\log _{2}$ difference of the respective female and male parent from the family progeny was determined in order to assess global inheritance patterns for all biomass-related traits in each family (Fig. 5). The diploid $\mathrm{F}_{2} S$. purpurea family 317 showed the most conserved inheritance for all traits, whereas the diploid $\mathrm{F}_{1} S$. purpurea family 82 showed greater levels of both P1- and P2-dominant as well as underdominant inheritance. The reciprocal interspecific diploid families 407 and 421 showed strong patterns of dominance, almost exclusively in the direction of the $S$. viminalis parent species. While stem traits for the triploid $S$. purpurea $\times S$. miyabeana family 415 primarily displayed P2-dominant inheritance, foliar traits within the family reflected more conserved or additive inheritance. The triploid $S$. viminalis $\times$ S. miyabeana family 423 showed strong P1-dominant inheritance for all traits, comparable to the diploid S. viminalis $\times$ S. purpurea family 421. Although many traits in family 423 showed P1-dominant inheritance, conserved or additive inheritance for foliar traits were predominant, compared to that of stem traits in the same 
454 family. Unlike triploid family 423, the triploid S. miyabeana $\times$ S. viminalis family 430 had the 455 greatest number of transgressive traits compared to all other families and showed nearly equal 456 P1- and P2-dominant inheritance patterns.

457 The heterozygous nature of Salix prevents a genetically uniform $\mathrm{F}_{1}$ and both hybrid vigor and 458 hybrid necrosis can be represented by siblings of the same cross. Here, we demonstrate that 459 triploid shrub willow hybrids, derived from diploid and tetraploid parents of different species, 460 exhibit both dominant and transgressive phenotypic expression. Most notably, this was observed 461 for biomass growth traits for crosses between Salix Sections Helix and Vetrix.

\section{Conclusion}

463 The results outlined here corroborate consistent findings that triploids produce greater biomass

464 yields than their diploid or tetraploid parents. Heterosis for many of the extensive traits collected 465 in the greenhouse also showed heterosis in the field, with consistently greater total stem volume 466 among triploid individuals. The genetic basis of heterosis in willows is not well understood, and 467 further work on characterizing this phenomenon will support community efforts in build a toolkit 468 for improving this sustainable, fast-growing bioenergy crop.

\section{Declarations:}

470 Funding: This research was supported by the U.S. Department of Energy, Office of Science,

471 Office of Biological and Environmental Research (grant no. DE-SC0008375) and US

472 Department of Agriculture National Institute for Food and Agriculture (grant no. 2018-68005-

$47327925)$.

474 Conflicts of Interest: The authors declare that they have no conflicts of interest.

475 Availability of data and material: All data not presented in the paper or supplementary material 476 will be made available upon reasonable request to the corresponding author. 
477 Acknowledgements: We are grateful to Smart Lab members Curt Carter, Lauren Carlson, and 478 Dawn Fishback for their excellent technical assistance, and to Fred Gouker and Eric Fabio for 479 assistance with harvesting and processing plants. 


\section{References}

1. Smart LB, Cameron KD (2012) Shrub Willow. In: Kole C, Joshi CP, Shonnard DR (eds) Handbook of Bioenergy Crop Plants. CRC Press, Boca Raton, FL, pp 687-708. https://doi.org/10.1201/b11711-32

2. Lauron-Moreau A, Pitre FE, Argus GW, Labrecque M, Brouillet L (2015) Phylogenetic relationships of American willows (Salix L., Salicaceae). PLoS ONE 10:e0121965. https://doi.org/10.1371/journal.pone.0121965

3. Argus GW (1997) Infrageneric classification of Salix (Salicaceae) in the New World. Syst Bot Monogr 52:1-121.

4. Argus GW (1974) An experimental study of hybridization and pollination in Salix (willow). Can J Bot 52:1613-1619. https://doi.org/10.1139/b74-212

5. Tamura S, Kudo G (2000) Wind pollination and insect pollination of two temperate willow species, Salix miyabeana and Salix sachalinensis. Plant Ecol 147:185-192. https://doi.org/10.1023/A:1009870521175

6. Percy DM, Argus GW, Cronk QC, Fazekas AJ, Kesanakurti PR, Burgess KS, Husband BC, Newmaster SG, Barrett SCH, Graham SW (2014) Understanding the spectacular failure of DNA barcoding in willows (Salix): Does this result from a trans-specific selective sweep? Mol Ecol 23:4737-4756. https://doi.org/10.1111/mec.12837

7. Hardig TM, Brunsfeld SJ, Fritz RS, Morgan M, Orians CM (2000) Morphological and molecular evidence for hybridization and introgression in a willow (Salix) hybrid zone. Mol Ecol 9:9-24. https://doi.org/10.1046/j.1365-294X.2000.00757.x

8. Lin J, Gibbs JP, Smart LB (2009) Population genetic structure of native versus naturalized sympatric shrub willows (Salix: Salicaceae). Am J Bot 96:771-785. https://doi.org/10.3732/ajb.0800321

9. Heribert-Nilsson N (1918) Experimentelle studien uber variabiliät, Spaltung, Artibildung, und evoluation in der gattung Salix. Lunds Universitats Arsskrift N. F. Avd 2. 
10. Karp A, Hanley S, Trybush S, Macalpine W, Pei MH, Shield I (2011) Genetic improvement of willow for bioenergy and biofuels. J Integ Plant Biol 53. https://doi.org/10.1111/j.17447909.2010.01015.x

11. Kuzovkina YA, Weih M, Romero MA, Charles J, Hust S, McIvor I, Karp A, Trybush S, Labrecque M, Teodorescu TI, Singh NB, Smart LB, Volk TA (2008) Salix: Botany and Global Horticulture. Horticultural Reviews. John Wiley \& Sons, Inc., pp 447-489. https://doi.org/10.1002/9780470380147.ch8

12. Birchler JA, Yao H, Chudalayandi S (2006) Unraveling the genetic basis of hybrid vigor. Proc Natl Acad Sci U S A 103:12957-12958. https://doi.org/10.1073/pnas.0605627103

13. Soltis DE, Albert VA, Leebens-Mack J, Bell CD, Paterson AH, Zheng C, Sankoff D, dePamphilis CW, Wall PK, Soltis PS (2009) Polyploidy and angiosperm diversification. Am J Bot 96:336-348. https://doi.org/10.3732/ajb.0800079

14. Wagner ND, He L, Hörandl E (2020) Phylogenomic relationships and evolution of polyploid Salix species revealed by RAD sequencing data. Front Plant Sci 11:1077. https://doi.org/10.3389/fpls.2020.01077

15. Chen ZJ (2010) Molecular mechanisms of polyploidy and hybrid vigor. Trends Plant Sci 15:57-71. https://doi.org/10.1016/j.tplants.2009.12.003

16. Volk TA, Abrahamson LP, Cameron KD, Castellano P, Corbin T, Fabio E, Johnson G, Kuzovkina-Eischen Y, Labrecque M, Miller R, Sidders D, Smart LB, Staver K, Stanosz GR, Rees Kv (2011) Yields of willow biomass crops across a range of sites in North America. Asp Appl Biol 112:67-74

17. Fabio ES, Volk TA, Miller RO, Serapiglia MJ, Kemanian AR, Montes F, Kuzovkina YA, Kling GJ, Smart LB (2017) Contributions of environment and genotype to variation in shrub willow biomass composition. Ind Crop Prod 108:149-161. https://doi.org/10.1016/j.indcrop.2017.06.030

18. Zsuffa L, Mosseler A, Raj Y (1984) Prospects for interspecific hybridization in willow for biomass production. In: Perttu KL (ed) Ecology and Management of Forest Biomass 
Production Systems. Report 15: Swedish University of Agricultural Sciences, Uppsala, Sweden.

19. Orians CM (2000) The effects of hybridization in plants on secondary chemistry: implications for the ecology and evolution of plant-herbivore interactions. Am J Bot 87:17491756. https://doi.org/10.2307/2656824

20. Hallgren P, Ikonen A, Hjältén J, Roininen H (2003) Inheritance patterns of phenolics in F1, F2, and backcross hybrids of willows: Implications for herbivore responses to hybrid plants. J Chem Ecol 29:1143-1158. https://doi.org/10.1023/A:1023829506473

21. Wang W, Carlson CH, Smart LB, Carlson JE (2020) Transcriptome analysis of contrasting resistance to herbivory by Empoasca fabae in two shrub willow species and their hybrid progeny. PLoS ONE 15:e0236586. https://doi.org/10.1371/journal.pone.0236586

22. Johansson LKH, Alstrom S (2000) Field resistance to willow leaf rust Melampsora epitea in inter- and intraspecific hybrids of Salix viminalis and S. dasyclados. Eur J Plant Pathol 106:763-769. https://doi.org/10.1023/a:1026573219481

23. Orians CM, Huang CH, Wild A, Dorfman KA, Zee P, Dao MTT, Fritz RS (1997) Willow hybridization differentially affects preference and performance of herbivorous beetles. Entomol Expr Appl 83:285-294. https://doi.org/10.1046/j.1570-7458.1997.00183.x

24. Orians CM, Griffiths ME, Roche BM, Fritz RS (2000) Phenolic glycosides and condensed tannins in Salix sericea, S. eriocephala and their F1 hybrids: not all hybrids are created equal. Biochem Syst Ecol 28:619-632. https://doi.org/10.1016/S0305-1978(99)00101-5

25. Orians CM, Fritz RS, Hochwender CG, Albrectsen BR, Czesak ME (2013) How slug herbivory of juvenile hybrid willows alters chemistry, growth and subsequent susceptibility to diverse plant enemies. Ann Bot 112:757-765. https://doi.org/10.1093/aob/mct002

26. Cameron KD, Phillips IS, Kopp RF, Volk TA, Maynard CA, Abrahamson LP, Smart LB (2008) Quantitative genetics of traits indicative of biomass production and heterosis in 34 full-sib F 1 Salix eriocephala families. Bioenerg Res 1:80-90. https://doi.org/10.1007/s12155008-9006-х 
27. Fabio ES, Kemanian AR, Montes F, Miller RO, Smart LB (2017) A mixed model approach for evaluating yield improvements in interspecific hybrids of shrub willow, a dedicated bioenergy crop. Ind Crop Prod 96:57-70. https://doi.org/10.1016/j.indcrop.2016.11.019

28. Nilsson-Ehle H (1936) A gigasform found in nature from Populus tremula. Hereditas 21:379-382.

29. Fabio ES, Volk TA, Miller RO, Serapiglia MJ, Gauch HG, Van Rees KC, Hangs RD, Amichev BY, Kuzovkina YA, Labrecque M (2016) Genotype by environment interactions analysis of North American shrub willow yield trials confirms superior performance of triploid hybrids. GCB Bioenergy 9:445-459. https://doi.org/10.1111/gcbb.12344

30. Serapiglia MJ, Gouker FE, Smart LB (2014) Early selection of novel triploid hybrids of shrub willow with improved biomass yield relative to diploids. BMC Plant Biol 14:74. https://doi.org/10.1186/1471-2229-14-74

31. Carlson CH, Gouker FE, Crowell CR, Evans L, DiFazio SP, Smart CD, Smart LB (2019) Joint linkage and association mapping of complex traits in shrub willow (Salix purpurea L.). Ann Bot 124:701-716. https://doi.org/10.1093/aob/mcz047

32. Carlson CH, Smart LB (2016) Electrical capacitance as a predictor of root dry weight in shrub willow (Salix; Salicaceae) parents and progeny. Appl Plant Sci 4:e1600031. https://doi.org/10.3732/apps.1600031

33. R Core Team (2017) R: A language and environment for statistical computing. R Foundation for Statistical Computing, Vienna, Australia.

34. Bates D, Mächler M, Bolker B, Walker S (2015) Fitting linear mixed-effects models using lme4. J Stat Soft 67:48. https://doi.org/10.18637/jss.v067.i01

35. Velazco JG, Rodriguez-Alvarez MX, Boer MP, Jordan DR, Eilers PHC, Malosetti M, van Eeuwijk FA (2017) Modelling spatial trends in sorghum breeding field trials using a twodimensional P-spline mixed model. Theor Appl Genet 130:1375-1392. https://doi.org/10.1007/s00122-017-2894-4 
36. Rodríguez-Álvarez MX, Lee D-J, Kneib T, Durbán M, Eilers P (2015) Fast smoothing parameter separation in multidimensional generalized P-splines: the SAP algorithm. Stat Comp 25:941-957. https://doi.org/10.1007/s11222-014-9464-2

37. Faliński JB (1980) Vegetation dynamics and sex structure of the populations of pioneer dioecious woody plants. Vegetatio 43:23-38. https://doi.org/10.1007/BF00121014

38. Crawford R, Balfour J (1983) Female predominant sex ratios and physiological differentiation in arctic willows. J Ecol 71:149-160. https://doi.org/10.2307/2259968

39. Alliende M, Harper J (1989) Demographic studies of a dioecious tree. I. Colonization, sex and age structure of a population of Salix cinerea. J Ecol 77:1029-1047. https://doi.org/10.2307/2260821

40. Dawson TE, Bliss L (1989) Patterns of water use and the tissue water relations in the dioecious shrub, Salix arctica: the physiological basis for habitat partitioning between the sexes. Oecologia 79:332-343. https://doi.org/10.1007/BF00384312

41. Alström-Rapaport C, Lascoux M, Gullberg U (1997) Sex determination and sex ratio in the dioecious shrub Salix viminalis L. Theor Appl Genet 94:493-497. https://doi.org/10.1007/s001220050442

42. Ueno N, Suyama Y, Seiwa K (2007) What makes the sex ratio female-biased in the dioecious tree Salix sachalinensis? J Ecol 95:951-959. https://doi.org/10.1111/j.13652745.2007.01269.x

43. Che-Castaldo C, Crisafulli CM, Bishop JG, Fagan WF (2015) What causes female bias in the secondary sex ratios of the dioecious woody shrub Salix sitchensis colonizing a primary successional landscape? Am J Bot 102 (8):1309-1322. https://doi.org/10.3732/ajb.1500143

44. Yin T, DiFazio SP, Gunter LE, Zhang X, Sewell MM, Woolbright SA, Allan GJ, Kelleher CT, Douglas CJ, Wang M, Tuskan GA (2008) Genome structure and emerging evidence of an incipient sex chromosome in Populus. Genome Res 18:422-430. https://doi.org/10.1101/gr.7076308 
613 45. Fabio ES, Smart LB (2018) Effects of nitrogen fertilization in shrub willow short rotation 614 coppice production - a quantitative review. GCB Bioenergy 10:548-564.

615 https://doi.org/10.1111/gcbb.12507

616 


\section{Tables}

618 Table 1. Description of intra- and interspecific shrub willow family parents, pedigree, ploidy-level, total 619 number of progeny $(\mathrm{N})$ included in the trial. Chi-square $\left(\chi^{2}\right)$ to test the null hypothesis of a 1:1 sex ratio $(\mathrm{F}$ $620=$ female, $M=$ male).

\begin{tabular}{llllcccccc}
\hline Family & Female & Male & Pedigree $^{\mathbf{1}}$ & Ploidy & N & F & M & F:M & $\chi^{2}$ \\
\hline 82 & 94006 & 94001 & S. pur $\times$ S. pur & $2 x$ & 100 & 71 & 29 & 2.44 & $46.2^{* * *}$ \\
317 & Wolcott & Fish Creek & S. pur $\times$ S. pur & $2 x$ & 482 & 266 & 216 & 1.23 & $5.19^{*}$ \\
407 & 94006 & Jorr & S. pur $\times$ S. vim & $2 x$ & 100 & 60 & 40 & 1.50 & $4.00^{*}$ \\
421 & 07-MBG-5027 & 94001 & S. vim $\times$ S. pur & $2 x$ & 100 & 53 & 47 & 1.13 & $0.36^{\text {ns }}$ \\
415 & 94006 & $01-200-003$ & S. pur $\times$ S. miy & $3 x$ & 100 & 56 & 44 & 1.27 & $1.44^{\text {ns }}$ \\
423 & 07-MBG-5027 & $01-200-003$ & S. vim $\times$ S. miy & $3 x$ & 63 & 36 & 27 & 1.33 & $1.26^{\text {ns }}$ \\
430 & 01-200-006 & Jorr & S. miy $\times$ S. vim & $3 x$ & 23 & 23 & 0 & inf & $23.0^{* * *}$ \\
425 & $01-200-006$ & SX64 & S. miy $\times$ S. miy & $4 x$ & 100 & 82 & 18 & 4.56 & $40.9^{* * *}$ \\
\hline
\end{tabular}

${ }^{1}$ Salix purpurea (S. pur), Salix viminalis $(S$. vim), and Salix miyabeana (S. miy).

${ }^{*} P<0.05,{ }^{* *} P<0.01,{ }^{* * *} P<0.001 ;$ ns $=$ non-significant 
641 Table 2. Trait descriptions, abbreviations, and units, and time of measurement in years post-coppice (Yr) 642 for field traits, and days after planting (dap) for greenhouse traits.

\begin{tabular}{|c|c|c|c|c|}
\hline Abbreviation & Trait & Units & Field (Yr) & Greenhouse (dap) \\
\hline \multicolumn{5}{|l|}{ Biomass } \\
\hline SDW & Total stem dry weight & $\mathrm{g}$ & - & 77 \\
\hline LDW & Total leaf dry weight & $\mathrm{g}$ & - & 77 \\
\hline RDW & Total root dry weight & $\mathrm{g}$ & - & 77 \\
\hline \multicolumn{5}{|c|}{ Stem measurements } \\
\hline HT & Plot height & $\mathrm{m}$ & $0,1,2$ & $14-77$ \\
\hline TSL & Total stem length & $\mathrm{cm}$ & - & $14-77$ \\
\hline MSL & Mean stem length & $\mathrm{cm}$ & - & $14-77$ \\
\hline STN & Stem number & \# & $0,1,2$ & $14-77$ \\
\hline DIA & Stem diameter & $\mathrm{mm}$ & 1,2 & 77 \\
\hline SA & Stem area & $\mathrm{cm}^{2}$ & 1,2 & 77 \\
\hline VOL & Stem volume & $\mathrm{cm}^{3}$ & 1,2 & 77 \\
\hline DVOL & Stem mass & g & 1,2 & 77 \\
\hline ASN & Axial stem number & \# & - & 35,70 \\
\hline \multicolumn{5}{|c|}{ Foliar measurements } \\
\hline LFA & Leaf area & $\mathrm{cm}^{2}$ & 1,2 & 70 \\
\hline LFL & Leaf length & $\mathrm{cm}$ & 1,2 & 70 \\
\hline LFW & Leaf width & $\mathrm{cm}$ & 1,2 & 70 \\
\hline LFP & Leaf perimeter & $\mathrm{cm}$ & 1,2 & 70 \\
\hline LFF & Leaf shape factor & $0-1$ & 1,2 & 70 \\
\hline LFR & Leaf aspect ratio & - & 1,2 & 70 \\
\hline LFDW & Leaf dry weight & g & 1,2 & 70 \\
\hline SLA & Specific leaf area & $\mathrm{cm}^{2} \mathrm{~g}^{-1}$ & 1,2 & 70 \\
\hline \multicolumn{5}{|c|}{ Canopy Architecture } \\
\hline CDIA & Crown diameter & $\mathrm{cm}$ & $0,1,2$ & - \\
\hline FORM & Crown form & $\circ$ & $0,1,2$ & - \\
\hline \multicolumn{5}{|c|}{ Wood Chemical Composition } \\
\hline HCL & Hemicellulose content & $\%$ & 2 & - \\
\hline CLS & Cellulose content & $\%$ & 2 & - \\
\hline LIG & Lignin content & $\%$ & 2 & - \\
\hline ASH & Ash content & $\%$ & 2 & - \\
\hline DEN & Wood density & $\mathrm{g} \mathrm{cm}^{-3}$ & 1,2 & - \\
\hline \multicolumn{5}{|c|}{ Physiology and Phenology } \\
\hline SPAD & SPAD & - & $0,1,2$ & $14,42,70$ \\
\hline RGR & Relative growth rate & $\mathrm{cm} \mathrm{d}^{-1}$ & $0,1.1,1.2,2$ & $14-77$ \\
\hline REC & Root electrical capacitance & $\mathrm{nF}$ & - & 77 \\
\hline STC & Stem color & $(0,1,2)$ & 0 & - \\
\hline PHE & Vegetative phenology & $0-5$ & - & $7,9,11,13,15$ \\
\hline
\end{tabular}




\section{Figure Captions}

649 Figure 1. Harvested dry biomass by family, genotype, and ploidy. Overlain (a) barplots of mean $( \pm \mathrm{SE})$

650 SDW, LDW, and RDW biomass by family. For each trait, letters above bars represent significant

651 differences by family according to Tukey's HSD groupings $(\alpha=0.05)$. The $(\mathbf{b})$ aboveground biomass

652

653

654

655

656

657

658

659

660

661

662

663

664

665

666

667

668

669

670

671

672

673

674

675

676

677

678 means $( \pm$ SE) all parent and progeny genotypes $(n=104)$ are shown in descending order. Bars are filled according to the ploidy of each genotype and filled circles below bars specify the location of the parents. Boxplot distributions depict the median and interquartile range (IQR \pm 1.5 ) of (c) biomass dry wt. (d) and biomass dry wt. ratios by ploidy, where asterisks denote significant differences at a Wilcoxon $P<0.05^{*}$, $<0.01 * *$, and $<0.001 * * *$.

Figure 2. Total aboveground dry biomass means of triploid families and respective female (P1) and male (P2) parents. Bars are colored according to ploidy-level (see legend). Asterisks *** above bars denote significant differences $(P<0.001)$.

Figure 3. Repeated physiological measurements by ploidy. Boxplot distributions depict the median and interquartile range (IQR \pm 1.5 ) of (a) phenological stages (PHE) at 7, 9, 11, and 13 days after planting (dap) as well as (b) SPAD values by ploidy. Asterisks above or below boxplots of diploids (beige), triploids (cyan), and tetraploids (dark grey) denote significant differences at a Wilcoxon $P<0.05^{*},<$ $0.01^{* *}$, and $<0.001^{* * *}$. The 15 dap stage is not shown because there were no significant differences by ploidy.

Figure 4. Midparent heterosis (MPH \%) for greenhouse collected traits in triploids and tetraploids. Boxplot distributions are shown as the percent deviation of the hybrid from the midparent and depict the median and interquartile range (IQR \pm 1.5 ) of MPH for each trait by family, which are filled according to the legend above panels.

Figure 5. Inheritance patterns growth traits among hybrid shrub willow families. Each point represents a single trait plotted as the $\log _{2}$ difference of the progeny from the female $\left(\log _{2}\left(\mathrm{~F}_{1} / \mathrm{P} 1\right)\right.$, horizontal axis) and male $\left(\log _{2}\left(F_{1} / P 2\right)\right.$, vertical axis) parents. Stem traits are characterized by filled black points and foliar traits, by filled white points. Red lines passing through each point represents the corresponding \pm standard error of the family mean.

Figure 6. Midparent heterosis (MPH \%) for field collected traits in triploids and tetraploids. Boxplot distributions are shown as the percent deviation of the hybrid from the midparent and depict the median and interquartile range (IQR \pm 1.5 ) of $\mathrm{MPH}$ for each trait by family, which are filled according to the legend above panels. 
Fig. 1

a

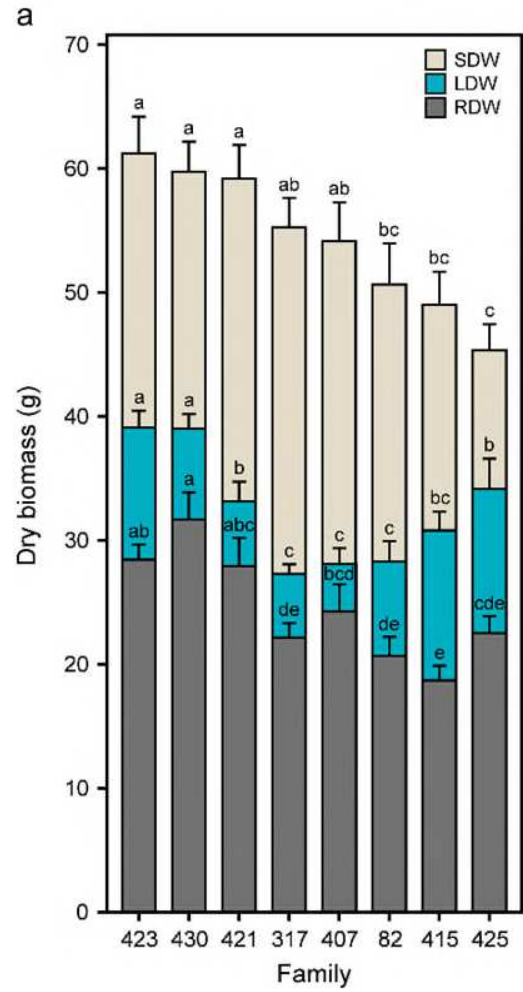

$b$
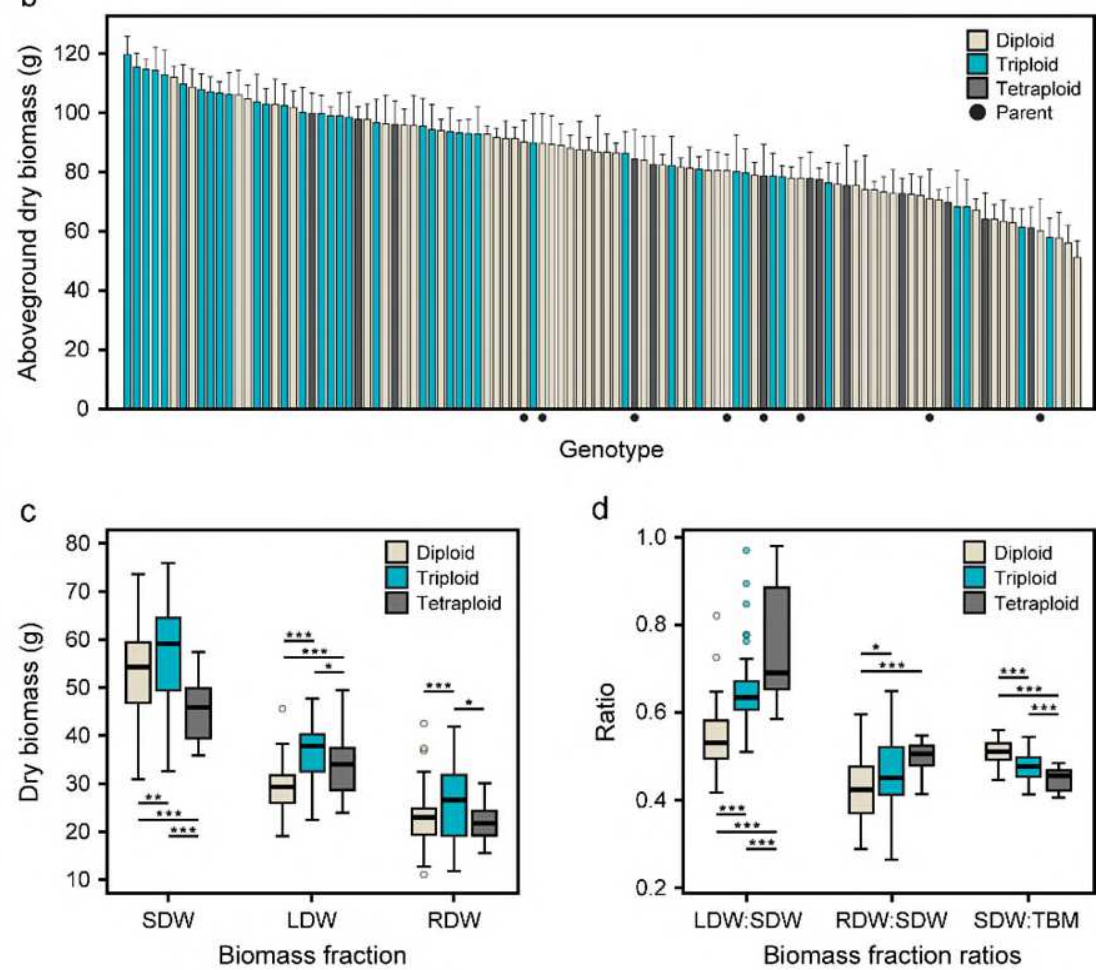

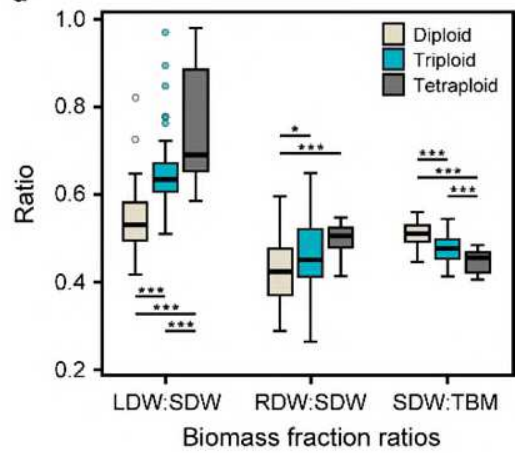

681 
Fig. 2

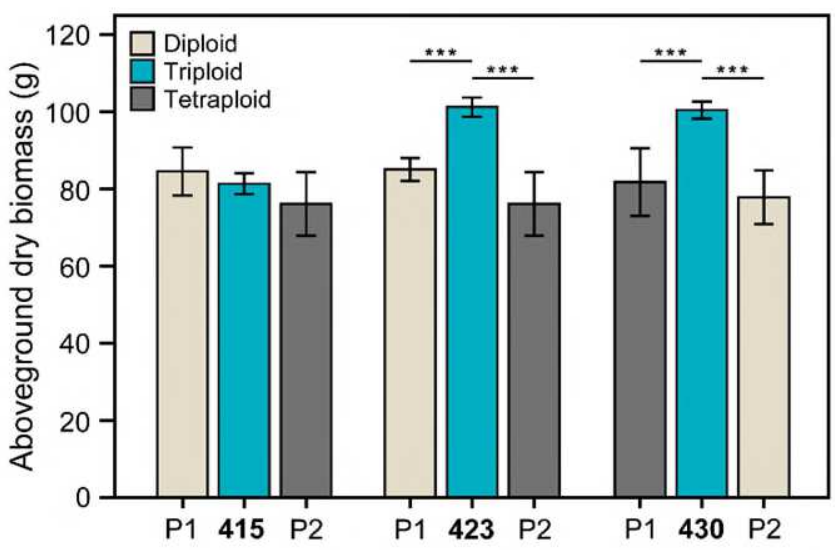

685

686

687

688

689

690

691

692

693

694

695

696

697

698

699

700

701

702

703

704

705 
Fig. 3
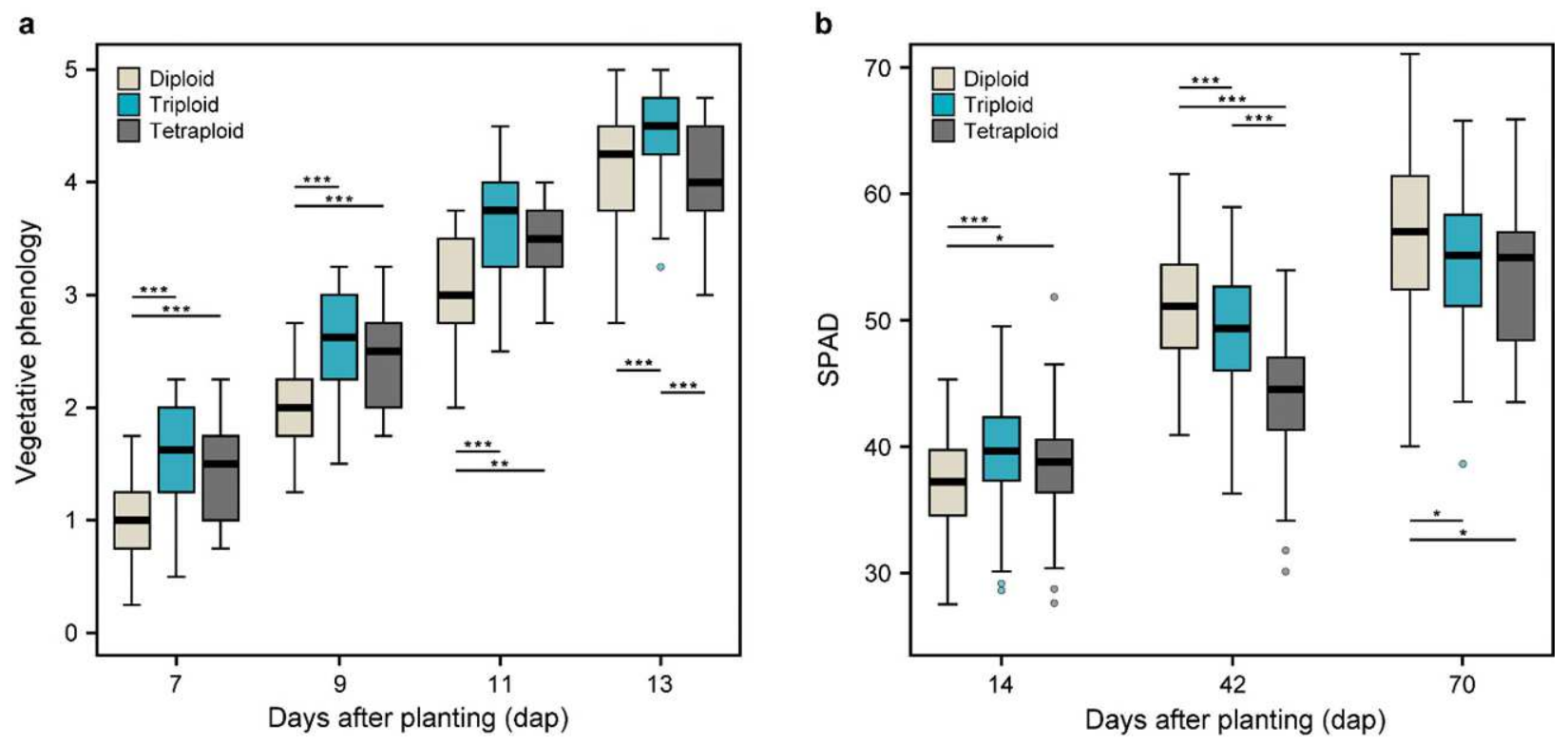

707

708

709

710

711

712

713

714

715

716

717

718

719

720

721

722

723

724

725 
Fig. 4
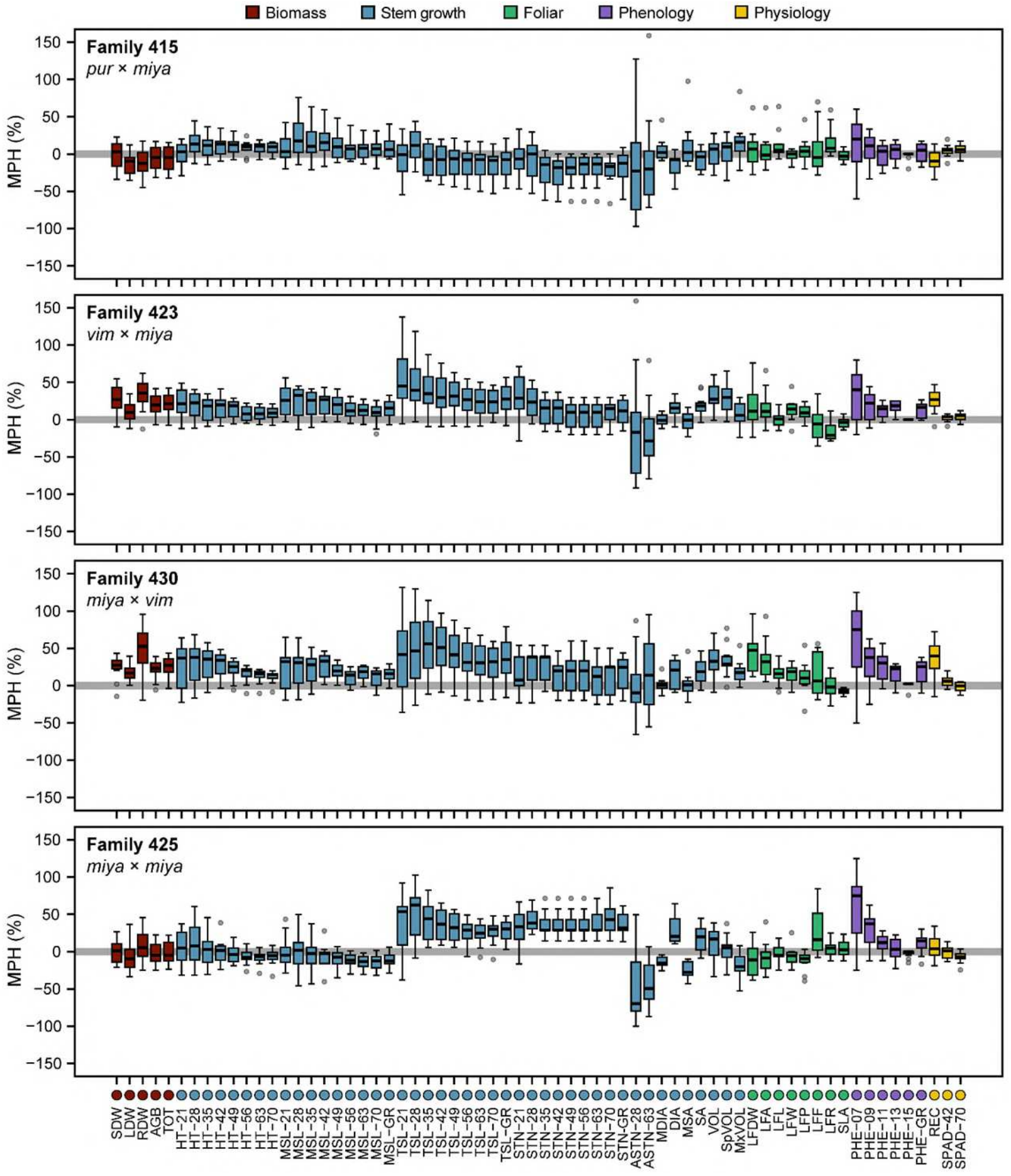
Fig. 5
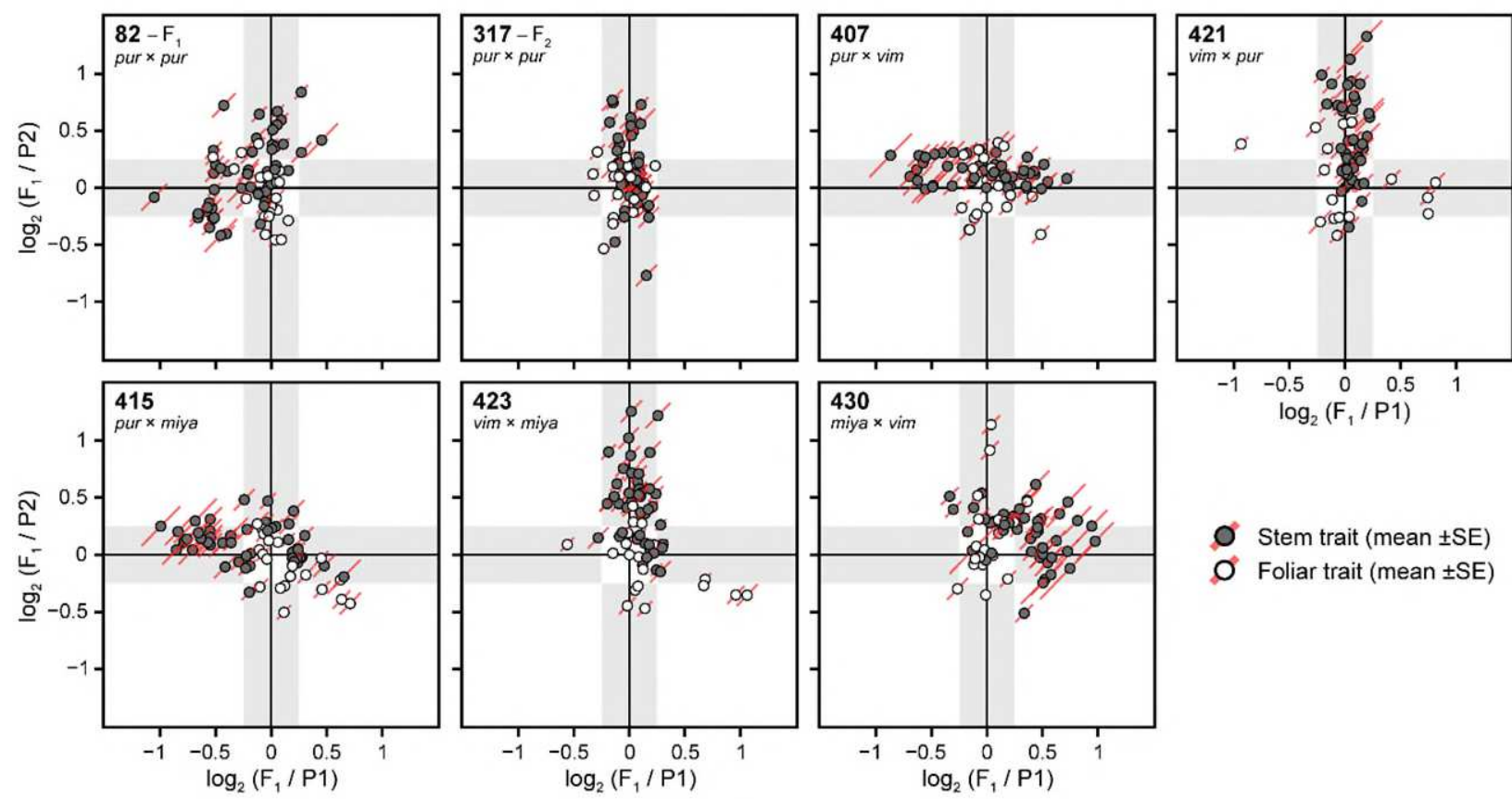

733

734

735

736

737

738

739

740

741

742

743

744

745

746

747

748

749

750 
Fig. 6
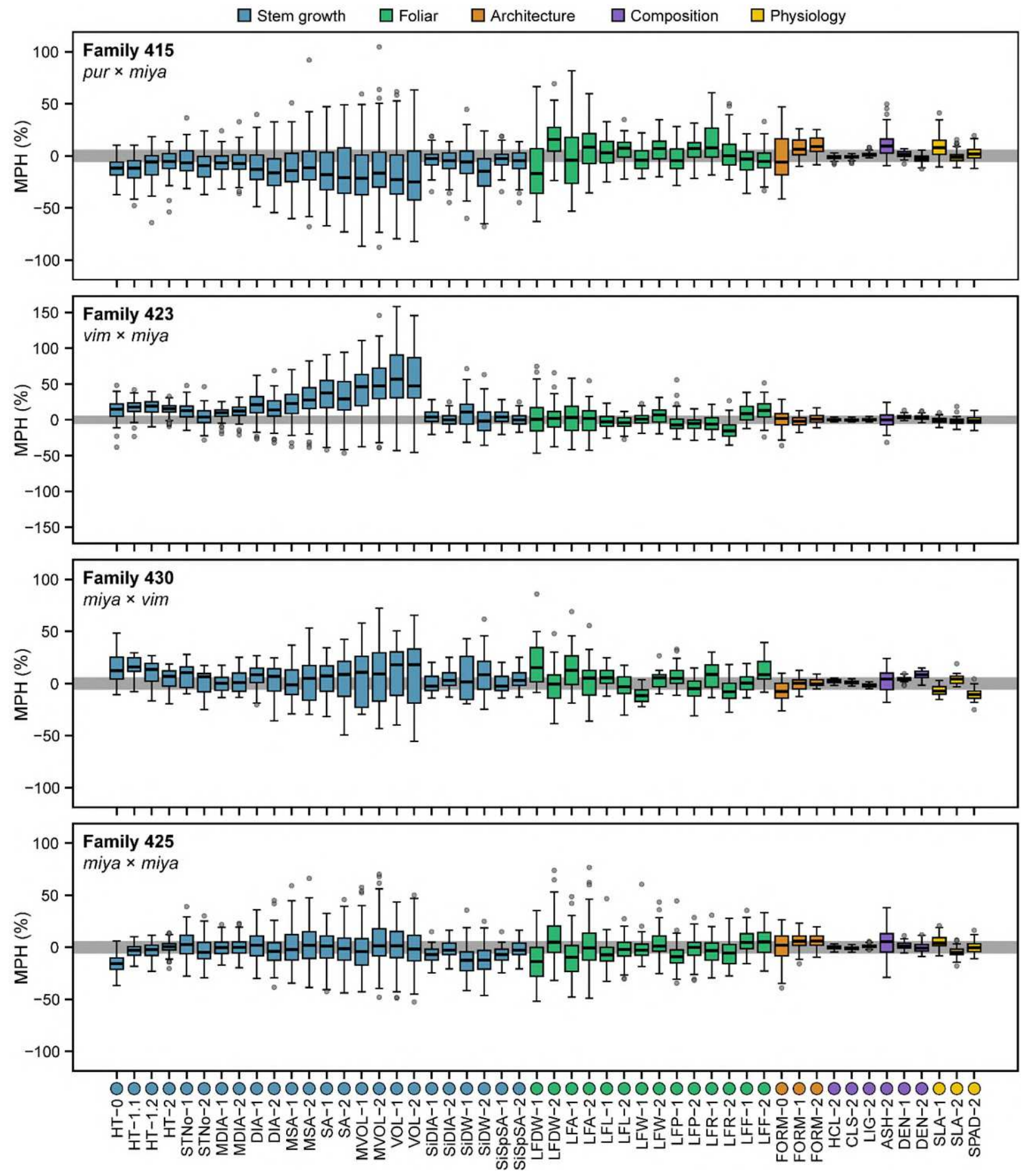


\section{Supplementary Material}

757 Supplementary Figure S1. Aerial image of the field trial located at Cornell AgriTech (Geneva, NY).

758 Supplementary Figure S2. Midparent heterosis (MPH \%) for greenhouse collected traits in diploids.

759 Boxplot distributions are shown as the percent deviation of the hybrid from the midparent and depict the

760 median and interquartile range (IQR \pm 1.5 ) of MPH for each trait by family, which are filled according to

761 the legend above panels.

762 Supplementary Figure S3. Pairwise correlations of biomass traits collected in the greenhouse. The 763 correlation matrix was re-ordered by hierarchical clustering using the average distance method. Beneath 764 trait abbreviations in the first row and in the final column, filled-circles highlight major trait classes 765 detailed in the legend. Increasing in intensity with higher absolute Pearson correlation coefficients $(r)$, 766 positive correlations are illustrated by filled blue squares and negative correlations by filled-red squares. 767 Non-significant correlations $(P>0.01)$ were left blank. Significance levels were used to scale the area of 768 each square, such that smaller squares represent correlations with lower significance and larger squares represent those showing more significance.

Supplementary Figure S4. Pairwise correlations of biomass traits collected in the field. The correlation matrix was re-ordered by hierarchical clustering using the average distance method. Beneath trait abbreviations in the first row and in the final column, filled-circles highlight major trait classes detailed in the legend. Increasing in intensity with higher absolute Pearson correlation coefficients $(r)$, positive correlations are illustrated by filled blue squares and negative correlations by filled-red squares. Nonsignificant correlations $(P>0.01)$ were left blank. Significance levels were used to scale the area of each square, such that smaller squares represent correlations with lower significance and larger squares represent those showing more significance.

778 Supplementary Figure S5. Wood chemical composition associations from second year post-coppice measurements. Points within each scatterplot are colored according to individual ploidy-level, according to the legend above figure panels.

781 Supplementary Figure S6. Midparent heterosis (MPH \%) for field collected traits in diploids. Boxplot

782 distributions are shown as the percent deviation of the hybrid from the midparent and depict the median 783 and interquartile range (IQR \pm 1.5 ) of MPH for each trait by family, which are filled according to the 784 legend above panels. 
Figures
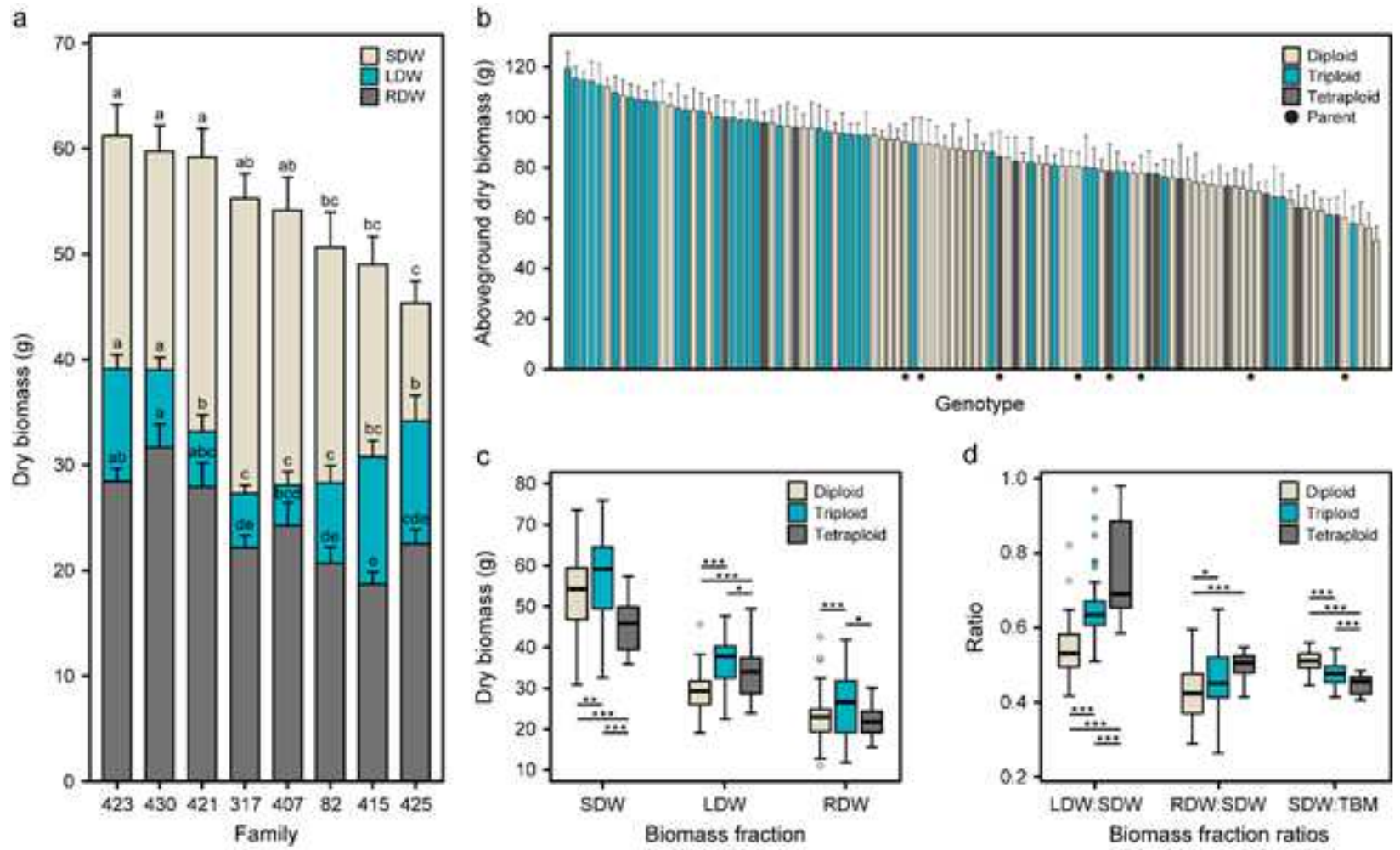

Figure 1

Harvested dry biomass by family, genotype, and ploidy. Overlain (a) barplots of mean ( \pm SE) SDW, LDW, and RDW biomass by family. For each trait, letters above bars represent significant differences by family according to Tukey's HSD groupings $(a=0.05)$. The $(b)$ aboveground biomass means $( \pm S E)$ all parent and progeny genotypes $(n=104)$ are shown in descending order. Bars are filled according to the ploidy of each genotype and filled circles below bars specify the location of the parents. Boxplot distributions depict the median and interquartile range (IQR \pm 1.5 ) of (c) biomass dry wt. (d) and biomass dry wt. ratios by ploidy, where asterisks denote significant differences at a Wilcoxon $\mathrm{P}<0.05^{*},<0.01^{\star \star}$, and $<0.001^{\star \star \star}$.

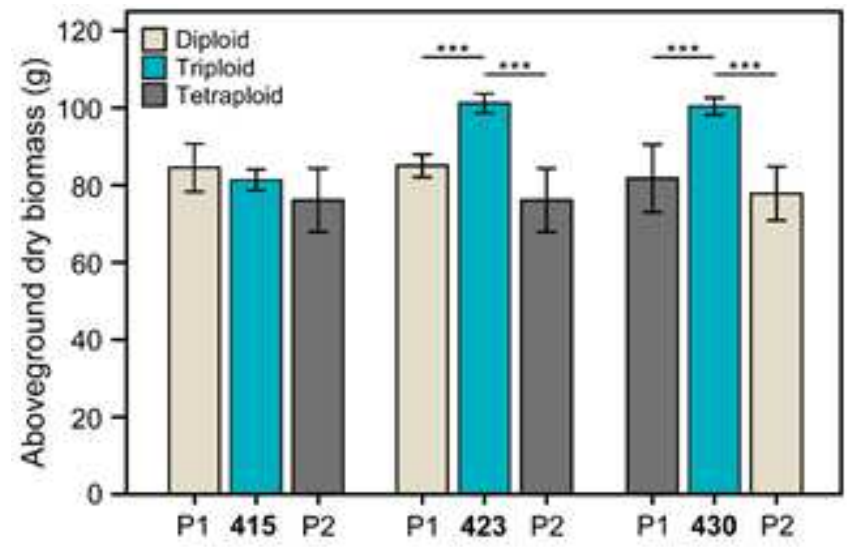

Figure 2 
Total aboveground dry biomass means of triploid families and respective female (P1) and male (P2)

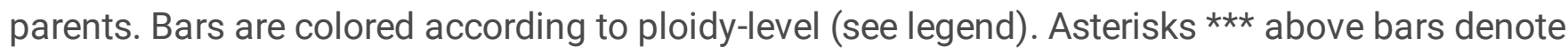
significant differences $(P<0.001)$.
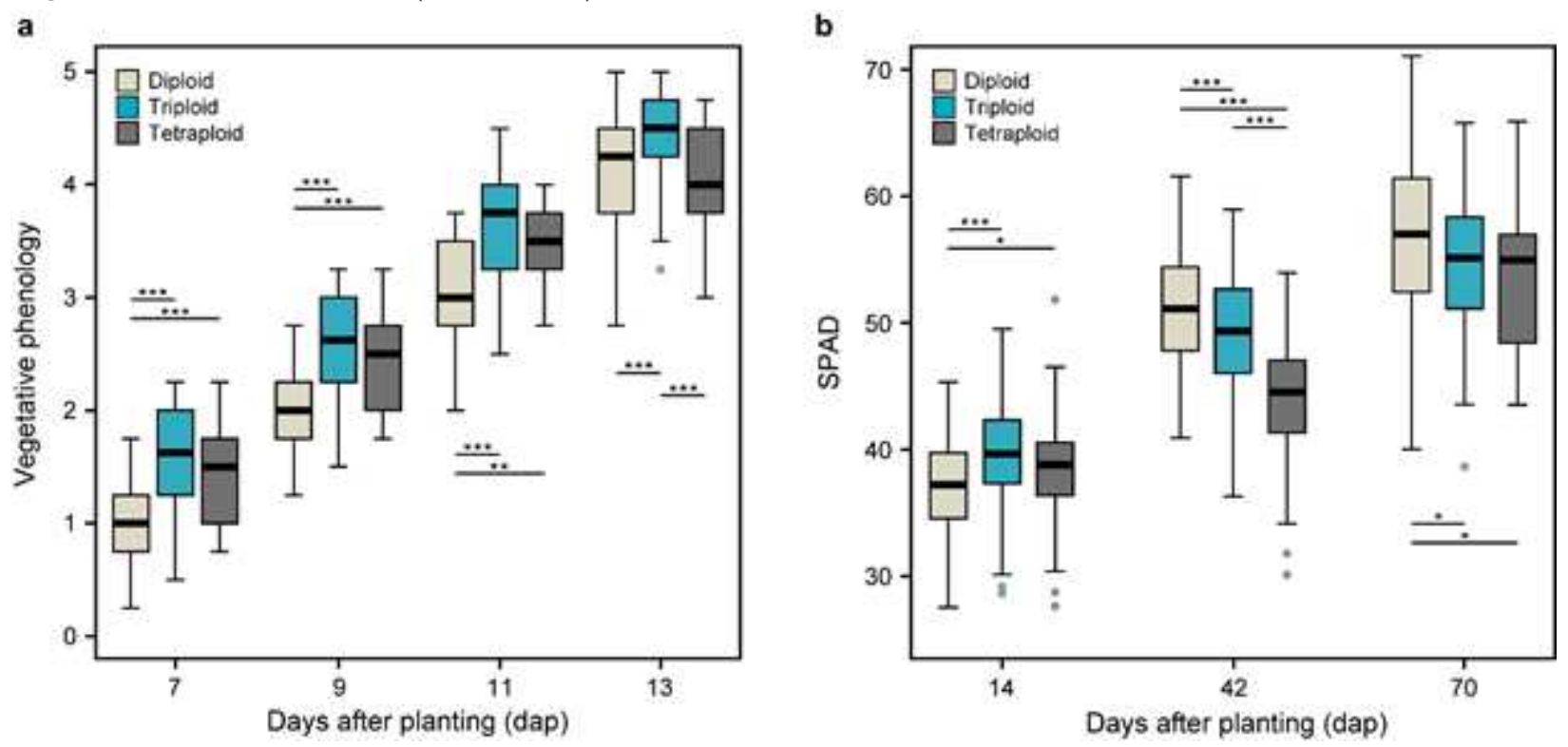

Figure 3

Repeated physiological measurements by ploidy. Boxplot distributions depict the median and interquartile range (IQR \pm 1.5 ) of (a) phenological stages (PHE) at $7,9,11$, and 13 days after planting (dap) as well as (b) SPAD values by ploidy. Asterisks above or below boxplots of diploids (beige), triploids (cyan), and tetraploids (dark grey) denote significant differences at a Wilcoxon $\mathrm{P}<0.05^{*},<0.01^{* *}$, and $<$ $0.001^{\star \star \star}$. The 15 dap stage is not shown because there were no significant differences by ploidy. 

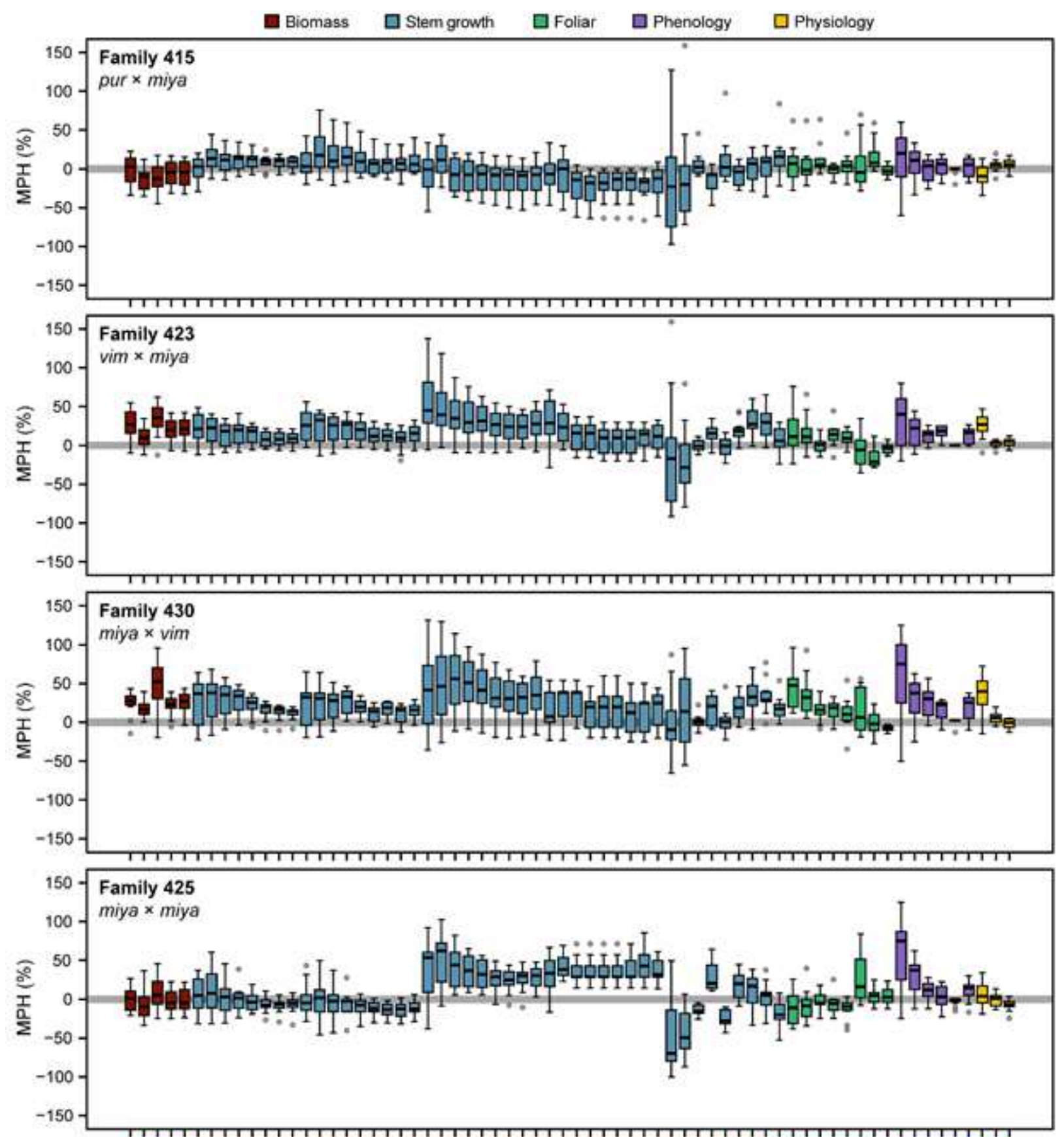

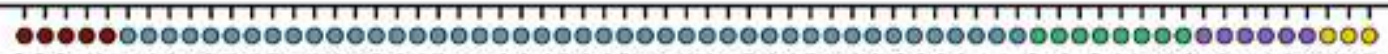

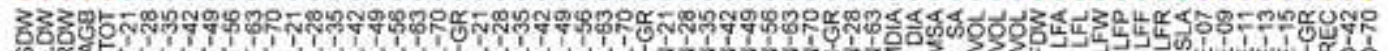

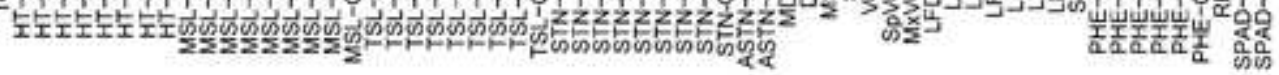

\section{Figure 4}

Midparent heterosis (MPH \%) for greenhouse collected traits in triploids and tetraploids. Boxplot distributions are shown as the percent deviation of the hybrid from the midparent and depict the median and interquartile range (IQR \pm 1.5 ) of $\mathrm{MPH}$ for each trait by family, which are filled according to the legend above panels. 

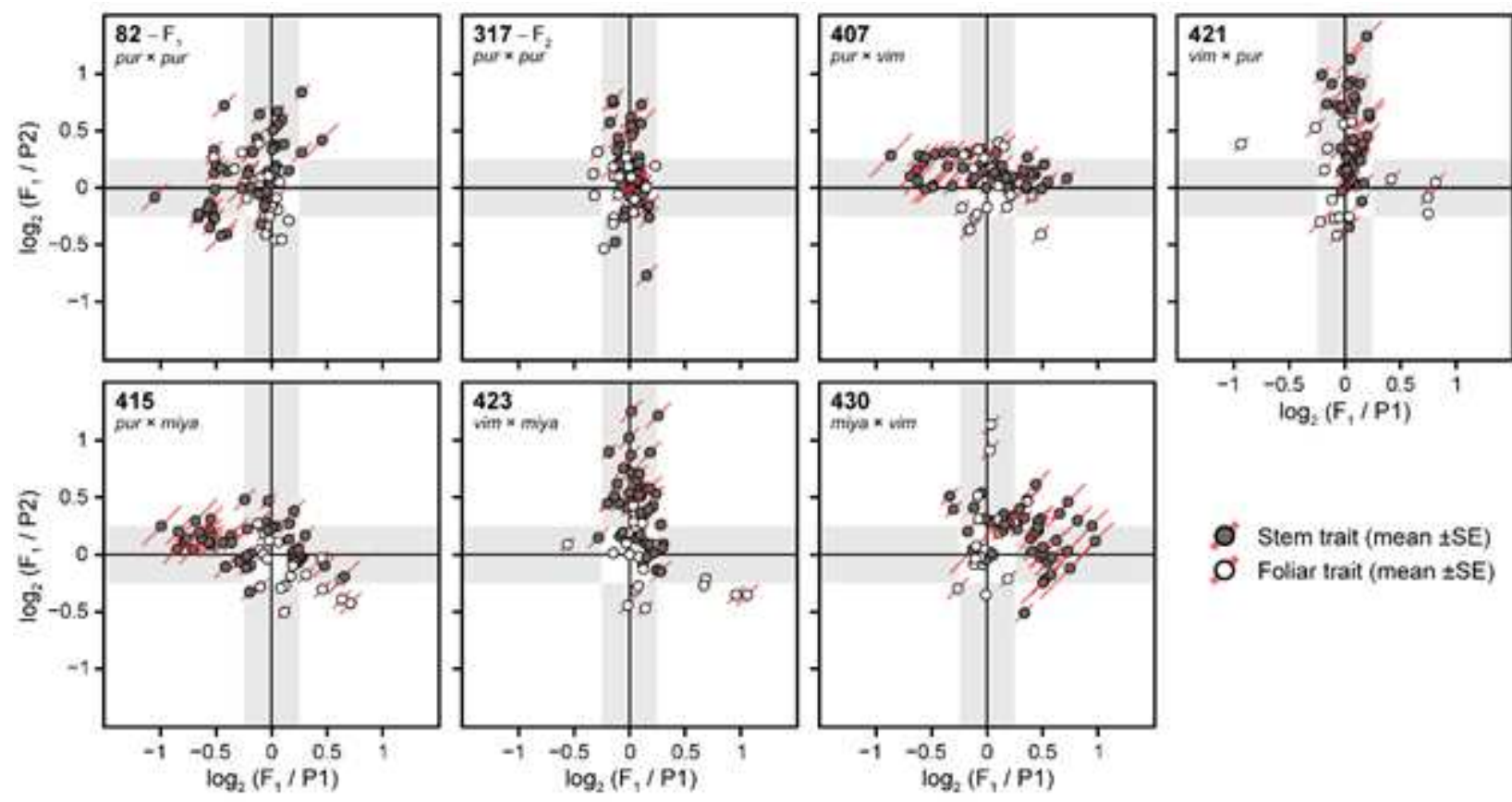

Figure 5

Inheritance patterns growth traits among hybrid shrub willow families. Each point represents a single trait plotted as the log2 difference of the progeny from the female (log2 (F1/P1), horizontal axis) and male (log2 (F1/P2), vertical axis) parents. Stem traits are characterized by filled black points and foliar traits, by filled white points. Red lines passing through each point represents the corresponding \pm standard error of the family mean. 

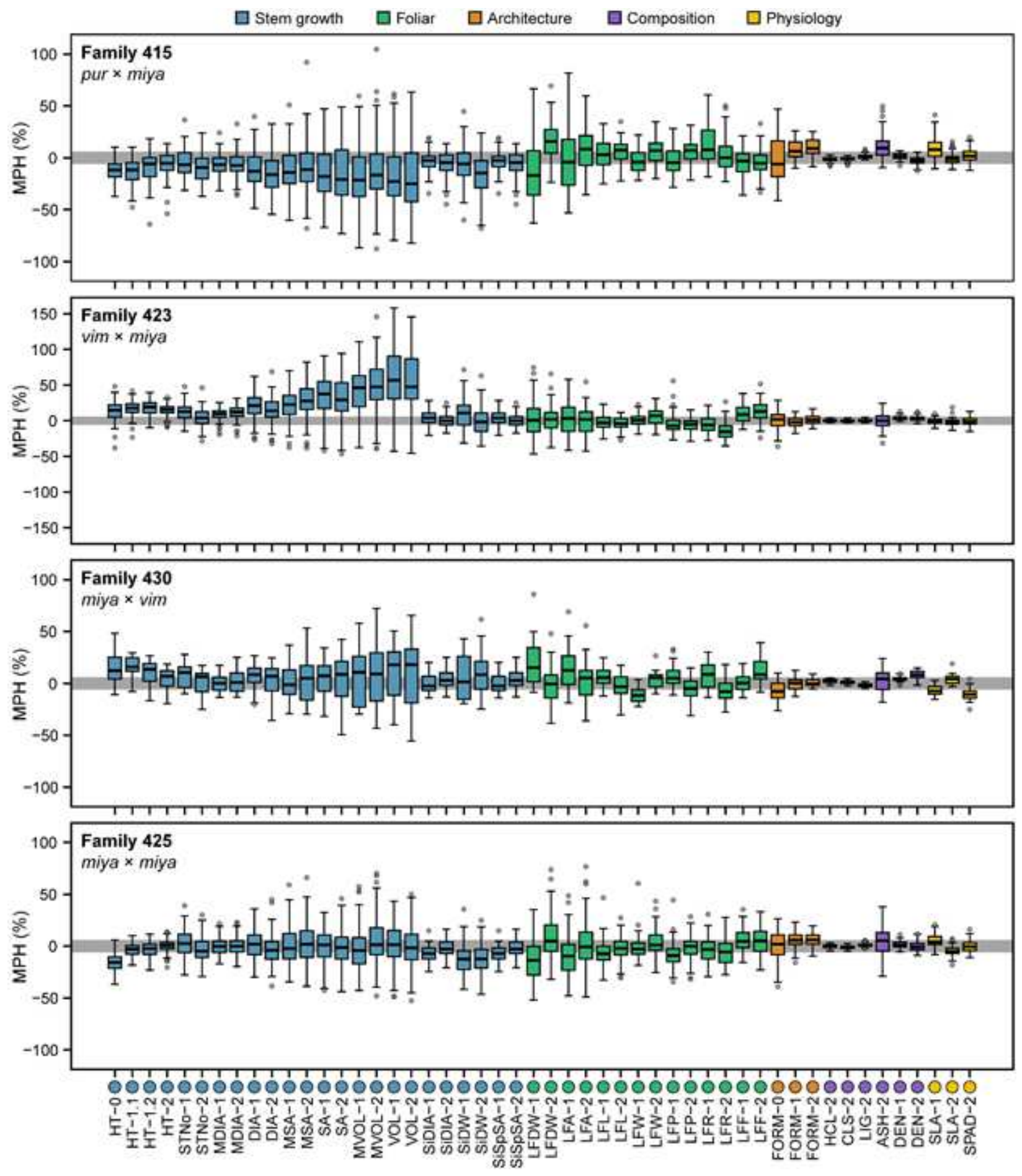

Figure 6

Midparent heterosis (MPH \%) for field collected traits in triploids and tetraploids. Boxplot distributions are shown as the percent deviation of the hybrid from the midparent and depict the median and interquartile range (IQR \pm 1.5 ) of MPH for each trait by family, which are filled according to the legend above panels.

\section{Supplementary Files}

This is a list of supplementary files associated with this preprint. Click to download. 
- CarlsonandSmartTriploidheterosisSupplementaryMaterial.pdf 